\title{
Factors impacting technology adoption in hospital bed logistics
}

\author{
Feibert, Diana Cordes; Jacobsen, Peter
}

Published in:

International Journal of Logistics Management

Link to article, DOI:

10.1108/IJLM-02-2017-0043

Publication date:

2019

Document Version

Peer reviewed version

Link back to DTU Orbit

Citation (APA):

Feibert, D. C., \& Jacobsen, P. (2019). Factors impacting technology adoption in hospital bed logistics.

International Journal of Logistics Management, 30(1), 195-230. https://doi.org/10.1108/IJLM-02-2017-0043

\section{General rights}

Copyright and moral rights for the publications made accessible in the public portal are retained by the authors and/or other copyright owners and it is a condition of accessing publications that users recognise and abide by the legal requirements associated with these rights.

- Users may download and print one copy of any publication from the public portal for the purpose of private study or research.

- You may not further distribute the material or use it for any profit-making activity or commercial gain

- You may freely distribute the URL identifying the publication in the public portal

If you believe that this document breaches copyright please contact us providing details, and we will remove access to the work immediately and investigate your claim. 


\section{Factors impacting technology adoption in hospital bed logistics}

\begin{tabular}{|r|l|}
\hline Journal: & International Journal of Logistics Management \\
\hline Manuscript ID & IJLM-02-2017-0043.R3 \\
\hline Manuscript Type: & Original Article \\
\hline Keywords: & $\begin{array}{l}\text { Healthcare logistics, Business process management, Information } \\
\text { technology }\end{array}$ \\
\hline Research Method: & Case study \\
\hline Geography: & Europe \\
\hline
\end{tabular}




\section{Factors impacting technology adoption in hospital bed logistics}

Purpose: This study aims to refine and expand technology adoption theory for a healthcare logistics setting by combining the technology-organizationenvironment (TOE) framework with a business process management (BPM) perspective. The paper identifies and ranks factors impacting the decision to implement instances of technologies in healthcare logistics processes.

Research design: A multiple case study is carried out at five Danish hospitals to investigate the bed logistics process. A combined technology adoption and BPM lens is applied to gain an understanding of the reasoning behind technology adoption.

Findings: A set of seventeen factors impacting the adoption of technologies within healthcare logistics were identified. The impact factors perceived as most important to the adoption of technologies in healthcare logistics processes relate to quality, employee work conditions and employee engagement.

Research limitations/implications: This paper seeks to understand how managers can use knowledge about impact factors to improve processes through technology adoption. The findings of this study provide insights about the factors impacting the adoption of technologies in healthcare logistics processes. Differences in perceived importance of factors enable 1) ranking of impact factors, and 2) prioritization of changes to be implemented. The study is limited to five hospitals, but is expected to be representative of public hospitals in developed countries and applicable to similar processes.

Originality/value: The study contributes to the empirical research within the field of BPM and technology adoption in healthcare. Furthermore, the findings of this study enable managers to make an informed decision about technology adoption within a healthcare logistics setting.

Keywords: healthcare logistics; business process management; technology adoption; technology-organization-environment framework

\section{Introduction}

Healthcare systems around the world face the challenge of rising healthcare costs.

Expectations of high quality care together with an ageing population and more

sophisticated treatments have led to more expensive healthcare provision (OECD, 2015;

WHO, 2010). Thus, there is an increasing pressure to provide high quality care at lower costs. One opportunity for reducing healthcare costs is by addressing logistics

expenditure in hospitals. Logistics activities account for more than $30 \%$ of hospital

costs, half of which could be eliminated by applying best practices (Aptel et al., 2009;

McKone-Sweet et al., 2005; Poulin, 2003). Main and supporting logistical flows in 
hospitals therefore hold great potential for cost reductions.

Hospitals are turning to manufacturing based supply chain management (SCM) best practices and business process management (BPM) concepts such as just-in-time (JIT) (Aptel and Pourjalali, 2001; Kumar, Ozdamar, et al., 2008; Kumar, DeGroot, et al., 2008), lean (Hicks et al., 2015; Joosten et al., 2009; Kollberg et al., 2007), total quality management (TQM) (Chen et al., 2004; Chow-Chua and Goh, 2000), business process reengineering (BPR) (Bertolini et al., 2011; Elkhuizen et al., 2006; van Lent et al., 2012) and automation (Granlund and Wiktorsson, 2013; Markin, 1994) in an effort to become more efficient and effective. However, hospitals are often left to their own experience to decide on a process design that suits their needs (van Lent et al., 2012). Similarly, whether to implement a technology is up to each hospital to decide and may differ depending on the focus areas of the hospital (Xie et al., 2016).

Introducing a new technology can significantly impact hospital costs and quality performance (Li and Benton, 2006) and can free up time for caretakers to perform other tasks (Bloss, 2011; Li and Benton, 2006). Technology adoption theory aims to predict under which circumstances a technology is adopted. The technology-organizationenvironment (TOE) framework identifies three contexts relevant to technology adoption, namely the technological, organizational and environmental contexts (Baker, 2012; Tornatzky and Fleischer, 1990). Applied in a healthcare logistics setting, the TOE framework may elucidate factors influencing the decision to adopt technologies to improve healthcare logistics processes.

A new technology will invariably affect the process in which the technology is implemented and the process design (Attaran, 2003; Karimi et al., 2007). Thus, technologies can greatly improve the efficiency of processes (Voss, 1988). Conversely, processes need to be aligned with the introduction of new technologies (Hung, 2006; 
Trkman, 2010). The TOE framework enables the assessment of potential technologies to be adopted. However, the main constructs of the TOE framework have not changed since it was developed in 1990 by Tornatzky and Fleischer (Baker, 2012), whereas the development in technologies has increased significantly over the past almost 30 years. Combining different theoretical models could contribute to a better understanding of technology adoption in organizations (Oliveira and Martins, 2011).

The TOE framework is somewhat static and fails to consider how the introduction of a new technology ties in with and affects the process in which the technology will operate, i.e. the dynamics of introducing a new technology. Consequently, the TOE framework does not consider how the introduction of a technology will improve or deteriorate the process and operations of a hospital. Supplementing the TOE framework with a process construct adds a dynamic perspective for predicting technology adoption in a constantly changing environment with fast paced technological advancements.

This paper seeks to identify the factors impacting the design of healthcare logistics processes by investigating why instances of technologies have been implemented in a hospital bed logistics process. The first research question is formulated as follows:

RQ1: Which factors impact the decision to implement instances of technologies in healthcare logistics processes?

Differences in process design provide different points of departure for introducing a new technology, both in terms of the extent of changes and the level of improvement increments. Failure to consider the current state of a process would therefore be to neglect the process improvement dimension and the benefits gained from 
a technology. To identify the impact factors in RQ1, a conceptual framework is developed based on the TOE framework combined with a BPM perspective.

Organizations operate under different circumstances and the benefits reaped from a technology therefore differ (Chan et al., 2001). Hence, organizations must select a technology that best fits their specific needs depending on the context in which the hospital operates. The factors impacting the decision to adopt a technology may therefore differ in importance depending on the context, e.g. industry, market segment and corporate strategy. A second research question is therefore investigated:

RQ2: How do the identified impact factors differ in terms of importance for the decision to adopt a technology within healthcare logistics processes?

This study aims to refine and expand technology adoption theory for a healthcare logistics setting by applying a combined technology adoption and BPM lens to a multiple case study of the bed logistics process in five Danish hospitals. The study therefore contributes to technology adoption literature and healthcare logistics literature by providing a set of factors impacting the decision to adopt technological innovations in a healthcare setting. Furthermore, the study illustrates how the process perspective enriches the TOE framework and in turn how the TOE framework enhances BPM theory.

This paper is organized as follows. A literature review is provided linking technology adoption to BPM for a healthcare logistics setting. The research method is then described, following a presentation of the results. Finally, the paper discusses and concludes on the results of the study.

\section{Literature review}

The following literature review covers four areas: 1) logistics processes in healthcare, 2) technologies in healthcare logistics, 3) technology adoption and TOE, and 4) BPM in 
healthcare. The literature review follows a sequence that logically links technology adoption to BPM for a healthcare logistics setting. By providing this trail of evidence from literature, the key elements of the study aims, research questions and objectives are covered and the link between them established. In relation to the RQs, the first section of the literature review provides the contextual background of the investigated processes. The second and third section relate to the technological aspect of the RQs, and the fourth section underpins and further justifies the importance of the BPM dimension in explaining the adoption of technologies in a healthcare logistics setting.

\title{
Logistics processes in healthcare
}

Logistics relates to the movement and transmittal of goods, services and information (Lummus et al., 2001) and is closely related to SCM, which is reflected in the definition of logistics management provided by the Council of Supply Chain Management Professionals (Council of Supply Chain Management Professionals, 2016):

\begin{abstract}
Logistics management is that part of supply chain management that plans, implements, and controls the efficient, effective forward and reverses flow and storage of goods, services and related information between the point of origin and the point of consumption in order to meet customers' requirements.
\end{abstract}

There has been a growing interest in the field of healthcare operations and SCM (Volland et al., 2016), including the selection and design of the service delivery system (Dobrzykowski et al., 2014). E.g. Spens and Bask (2002) expand a SCM framework by applying the framework to a blood transfusion supply chain and Narayana et al. (2014) investigate the factors impacting the reverse pharmaceutical supply chain.

A process oriented approach to SCM can improve supply chain performance (Aronsson et al., 2011; Kumar, Ozdamar, et al., 2008). Principles such as six sigma (Jin et al., 2008), lean (Souza, 2009), JIT (Jarrett, 1998; Kumar, Ozdamar, et al., 2008; Pan 
and Pokharel, 2007), TQM (Heinbuch, 1995), BPR (Chow-Chua and Goh, 2000;

Elkhuizen et al., 2006; Ho et al., 1999), and cellular operations (Parnaby and Towill, 2009) have therefore been applied to healthcare logistics processes. However, the extent of the field continues to be limited.

The process investigated in this paper is the bed logistics process, which includes the flow of beds and the flow of patients. A survey of Dutch hospitals revealed that the most prevalent process management approaches in patient logistics are care pathways and benchmarking, followed by BPR and lean management. However, half of the survey hospitals had not achieved their goals (van Lent et al., 2012). This suggests a need for more research on how to successfully improve patient and bed logistics from a process perspective.

Beds are a scarce resource and hospitals are faced with both poor bed utilization and bed shortages (Bekker and Koeleman, 2011; Holm et al., 2013; Schmidt et al., 2013). At the same time, the growing demand for healthcare resources increases the pressure for better utilization of bed capacity (Bekker and Koeleman, 2011). A number of constraints in the bed logistics process contribute to the complexity of managing the process; e.g. single rooms, no mixed-sex rooms, incompatibility between pathologies, and contagiousness. Bed management units must solve these issues in a context of high uncertainty as treatment outcomes are not fully predictable and as emergency patients need immediate treatment (Schmidt et al., 2013). Consequently, changes are repeatedly made due to acute patients and inaccuracy in expected length of stay (Bachouch et al., 2012). Computer aided decision support can help overcome the challenges in the bed logistics process and improve bed utilization by taking different constraints into account (Schmidt et al., 2013). Operations research approaches such as simulation studies (Kim et al., 2000; Schmidt et al., 2013), scheduling (Bekker and Koeleman, 2011) and 
mathematical modelling (Bachouch et al., 2012; Utley et al., 2003) have been used to solve these optimization problems. Others have taken a more process oriented approach (Banerjee et al., 2008; Parnaby and Towill, 2009; Villa et al., 2009, 2014), but research in this area is more limited.

The provided literature study suggests a need for research on bed logistics, particularly on selecting the appropriate process design. This paper applies the less used process management approach to bed logistics and provides a framework that supports the assessment of process designs in terms of technology adoption and investigates the factors determining the adoption of technologies as part of the process design.

\section{Technologies in healthcare logistics}

Nurses spend as much as $30 \%$ of their time on logistics tasks such as tracking down medication and other supplies. Technologies can help care staff spend more time on patient care (Bloss, 2011; Granlund and Wiktorsson, 2013). Hence, technologies can improve process efficiency (Pokharel, 2005; Voss, 1988), provide cost savings, reduce data entry errors, and increase customer service levels (Pan and Pokharel, 2007). IT in particular can significantly influence an organization's overall logistics competence (Closs et al., 2006). The types of technologies applied in healthcare logistics processes undertake one of two types of tasks: information management or materials transport. Each of these types of technologies is described in the following.

Information management. IT can dramatically improve the accuracy, reliability, speed and productivity of logistics processes in hospitals (Su et al., 2011). Wamba and colleagues provide an extensive literature review on the application of RFID in healthcare and identify three overall applications: 1) patient management, 2) asset management, and 3) staff management. Benefits include efficiency, quality and 
management gains (Wamba et al., 2013), increased productivity, and reduced inventory loss (Kumar and Rahman, 2014).

Barcodes and RFIDs can serve the same purpose. RFIDs can provide more benefits, albeit at a higher cost. A study by Romero and Lefebvre found that combining the use of barcodes and RFIDs resulted in better inventory management and less inventory loss, decreasing the amount of manual labor, length of procurement cycles and number of recall activities (Romero and Lefebvre, 2015).

Materials transport. Automated guided vehicles (AGVs) are mobile robots that can autonomously navigate and transport items such as medicine, lab results, food, linen, equipment and other supplies, allowing nurses to spend more time with patients (Bloss, 2011; Granlund and Wiktorsson, 2013; Kumar and Rahman, 2014; Landry and Philippe, 2004). Another technology used for transporting items in hospitals is pneumatic tubes where items are transported in canisters by using compressed air. Pneumatic tube systems have been widely used in laboratory practices to transport items such as blood samples (Al-Riyami et al., 2014; Granlund and Wiktorsson, 2013; Jørgensen et al., 2013).

The described technologies perform different types of activities but can serve the same purpose, i.e. to free up time for care personnel. To decide on which technologies to implement, different assessment and justification methods can be applied.

\section{Technology adoption and TOE}

There are several ways to assess and justify the implementation of a new technology. Technology assessment methods tend to focus on informing policy makers of the general impact of a new type of technology. E.g. health technology assessment informs policy makers about the efficacy, safety, and cost-effectiveness of technologies that solve a health problem and improve the quality of life (Ritrovato et al., 2015; WHO, 
2015). However, this paper is not concerned with solving a health problem as such or with designing a new technology, but rather the justification of technologies.

Meredith and Suresh distinguish between three methods for technology justification: strategic, economic and analytic (Meredith and Suresh, 1986). Strategic justification relates to considerations such as business objectives and competitive advantage. An example of an economic method is the calculation of payback time, e.g. (Granlund and Wiktorsson, 2013; Landry and Philippe, 2004; Reyes et al., 2012). The analytic approach includes techniques such as the weighted factor model and the Analytic Hierarchy Process (AHP).

Whether a technology is adopted not only depends on an assessment of a given technology, but also on individual users' attitude toward the technology. The field of psychology thereby lends itself to explaining the adoption of technologies. Fishbein and Ajzen (1975) proposed the theory of reasoned action, suggesting that actual behavior depends on behavioral intention, which in turn is determined by an individual's attitude towards a given behavior and the subjective norm associated with that behavior. The theory of planned behavior is an extension of the theory of reasoned action with the addition of perceived behavioral control as a factor influencing the intention to use a technology (Ajzen, 1985).

Building on the theory of reasoned action paradigm, Davis (1985) proposed the technology acceptance model (TAM) to explain the user motivation and intent to accept or reject information systems. Over time, TAM has evolved from introducing the model, through model validation, model extension and model elaboration. In the final 1996 version of TAM, external variables were added as antecedents of user motivation (Venkatesh and Davis, 1996). Since then, several authors have identified different external variables of TAM (Lee et al., 2003); e.g. variables explaining the perceived 
usefulness of a system (Venkatesh and Davis, 2000) and variables determining perceived ease of use (Venkatesh, 2000).

Bagozzi (2007) critiques TAM for its simplicity and for the development in technology acceptance literature becoming fragmented, incoherent and chaotic due to the excessive number of variables identified for predicting user behavior. He argues that researchers should instead aim to deepen TAM by explaining the relationships between the motivational variables and between the intention to use a technology and actual behavior.

The technology adoption theories presented thus far relate to technology adoption for individuals. Oliveira and Martins (2011) review technology adoption literature at the firm level and argue that most models are derived from the diffusion of innovation (DOI) theory and the technology-organization-environment (TOE) framework. The TOE framework has been used in conjunction with other theories such as DOI and institutional theory. Tornatzky and Fleischer (1990) developed the TOE framework, which explains how a firm's context influences the adoption and implementation of technological innovations. The framework consists of the following three contexts: 1) technological context, 2) organizational context and 3) environmental context. The technological context refers to relevant technologies, i.e. those in use and those available in the market. Organizational context refers to organizational aspects such as scope, size, and managerial structure. Finally, environmental context refers to the setting in which the firm operates, i.e. the industry, competitors and government. Several studies have since validated the TOE framework and additionally identified underlying factors for particular technologies or contexts (Baker, 2012).

In DOI theory, Rogers identified characteristics for three contexts to better understand technology adoption: individual (leader) characteristics, internal 
organizational structure characteristics, and external organizational characteristics (Rogers, 1995). Looking at the DOI and TOE contexts, the similarities are evident. First, individual leader characteristics and internal characteristics of organizational structure of DOI are comparable to the organizational context in TOE. Second, the external characteristics of the organization in DOI correspond to the environmental context of TOE. Finally, the implicit emphasis of technological attributes in the DOI is similar to the technological context of the TOE (Baker, 2012).

TOE is applicable for a healthcare environment and factors influencing the adoption of technologies in healthcare have been investigated, e.g. for RFID adoption (Cao et al., 2014), the adoption of telemedicine (Hu et al., 2000) and electronic signature (Chang et al., 2007). Furthermore, TOE has been applied in logistics and supply chain management settings, e.g. for patient tracking (Cao et al., 2014) and electronic supply chain systems (Lin, 2014).

The TOE framework was chosen as part of the theoretical lens of this study for a number of reasons. First, TOE was chosen because of its proven applicability for healthcare and logistics settings, e.g. (Cao et al., 2014; Lin, 2014). Second, the TOE framework was chosen because of its parsimonious attributes and broad applicability for different types of innovations (Baker, 2012). Third, as firms become more interconnected, the understanding of the environmental context becomes increasingly important and may differ across firms. Taking such different views of the environment into account would provide actionable insights for practitioners (Baker, 2012). This study focuses on the hospital bed logistics process and identifies technology adoption factors to be considered for practitioners within a healthcare logistics setting. The study thereby provides actionable insights for practitioners in this setting. 
The TOE framework has scarcely evolved since its initial development in 1990 and contributions mainly relate to identifying context specific factors rather than extending the framework with additional constructs (Baker, 2012). However, technological advancements mean that organizations are now faced with a wider array of technologies that are faster in terms of computing power. Oliveira and Martins (2011) argue that for future research in technology adoption, it is necessary to combine different theoretical models to better explain IT adoption. This study advances the TOE framework both in terms of context specific factors and in terms of adding a construct, i.e. the process construct. The process construct adds a time element as processes are carried out over a certain timespan. The increasing effect of technologies on time compression makes the enhanced framework more dynamic and sensitive to technological advancements. The TOE framework aims to explain the adoption of technologies as determined by the context (Tornatzky and Fleischer, 1990). However, the framework fails to consider the effects of introducing the technology, e.g. in terms of efficiency. Most organizations would hesitate to invest in new technologies without expecting operational gains ultimately reflected in the financial bottom line. Moreover, the benefits realized from introducing a technology differs between organizations depending on the specific circumstances of the organization (Chan et al., 2001). Thus, combining the TOE framework with the BPM perspective allows for taking into account both the effects on and effects of a technology to better explain technology adoption.

\section{Business process management in healthcare}

Similar to the introduction of technologies, companies can utilize BPM to improve a company's performance and provide a competitive advantage (Ho et al., 1999; Hung, 2006; Liu et al., 2011). BPM is a structured approach to analyzing and continually 
improving fundamental activities in a company's operations (Zairi, 1997). There are two distinct approaches to creating change in BPM: a radically oriented BPR approach and the incrementally oriented TQM approach (Hung, 2006). Moreover, BPM approaches can address different needs depending on variability in demand patterns. Thus, a lean approach to designing business processes can eliminate waste in a process and improve process efficiency for processes with low demand variability (Guimarães et al., 2013; Pilkington and Fitzgerald, 2006). In contrast, agility allows for responsiveness to changes in demand (Holweg, 2005). Lean and agility are often compared and can be combined in a leagile approach, e.g. (Aronsson et al., 2011).

To ensure the success of BPM efforts, Trkman identified a set of critical success factors, which relate to three constructs: 1) process design, 2) organizational structure, and 3) technologies. First, business processes should be standardized and aligned with strategic objectives and a focus on continuous improvement should be ensured (Armistead et al., 1999; Davenport and Short, 1990; Hung, 2006; Trkman, 2010; Zairi, 1997). Second, organizational structure and business processes should be aligned. Hence, training, employee empowerment and employee engagement are vital at the employee level, and management commitment is essential at the managerial level to sustain changes (Armistead et al., 1999; Ho et al., 1999; Hung, 2006; Trkman, 2010). Finally, continued alignment of technologies is imperative to the success of BPM (Hung, 2006). Thus, together with human resources and organizational change, technologies are enablers of process redesign.

Introducing BPM tools and methods in a healthcare context may not be straightforward due to the idiosyncratic nature of healthcare. As such, hospitals are complex systems consisting of unique and interrelated processes coordinated across several organizational units (Aronsson et al., 2011; Kannampallil et al., 2011; Lillrank 
et al., 2011). Problems are often specific to a healthcare context, making it difficult to standardize these processes (Helfert, 2009). Furthermore, healthcare processes are viewed as unpredictable, non-routine processes that make it hard to schedule production and to apply a process approach (Aronsson et al., 2011; Jarrett, 1998; Lillrank et al., 2011). The particular circumstances of a healthcare environment could therefore complicate the applicability of BPM approaches in healthcare.

Despite the specific challenges in healthcare operations, hospitals have managed to apply BPM tools and methods such as lean (Hicks et al., 2015; Joosten et al., 2009; Kollberg et al., 2007), JIT (Aptel and Pourjalali, 2001; Kumar, Ozdamar, et al., 2008; Kumar, DeGroot, et al., 2008), TQM (Chen et al., 2004; Chow-Chua and Goh, 2000) and BPR (Bertolini et al., 2011; Elkhuizen et al., 2006; van Lent et al., 2012) to reduce costs and improve quality of care. However, these managerial tools have not been systematically implemented in healthcare settings (Towill and Christopher, 2005; Yasin et al., 2002) and managers are often left to their own experience to decide which process management approach best fits their hospital (van Lent et al., 2012). The ability to assess a supply chain solution is therefore vital to identifying the best option for a particular hospital. However, there are certain challenges related to assessing performance of healthcare supply chains (Böhme et al., 2013), making it difficult to assess the value and success of a change (McKone-Sweet et al., 2005). Lega et al. (2012) argue for measuring five quality dimensions: 1) delivery performance, 2) time to deliver, 3) flexibility, 4) distribution of workloads, and 5) information accuracy and timeliness. The study by Lega and colleagues is limited to these five quality dimensions, but more research is needed to fully understand the performance dimensions of health supply chains to enable the assessment of possible supply chain solutions. 
In terms of demand patterns and uncertainty in healthcare, unpredictability is a product of both artificial variation introduced by the system itself and natural variation inherent to a healthcare system (Litvak et al., 2005; Litvak and Long, 2000; Noon et al., 2003; Walley et al., 2006). Artificial variation can be reduced by eliminating poor hospital practices (Litvak et al., 2005; Walley et al., 2006), thereby reducing waste and improving quality of care (Litvak and Long, 2000). To achieve better utilization of resources in a healthcare supply chain, Kumar et al. (2008) therefore propose a more process oriented system for redesigning healthcare supply chains. Thus, unpredictability should not inhibit the adoption of BPM in healthcare.

The application of lean and agile approaches is often associated with predictability and subsequently the level of certainty in demand patterns. Whereas lean responds poorly to variability and seeks to smooth out demand variability, an agile process strategy responds well to variability (Naylor et al., 1999). Aronsson et al. investigate the applicability of lean and agile processes in a healthcare supply chain. Agile processes are responsive and flexible while lean processes focus on eliminating waste in the process (Aronsson et al., 2011). Several examples of lean applications in healthcare exist, e.g. as reported by Souza (2009). Still, the application of lean remains narrow and tool focused rather than a system-wide philosophy (Radnor et al., 2012). As an example, Jarrett (1998) argues that JIT, i.e. a lean tool, is applicable in a healthcare setting and could reduce costs but that contingency plans should be in place in cases of disruption.

To accommodate both the need for a rapid response to variability and the increasing pressure for efficiency, several authors suggest a leagile process strategy for healthcare delivery systems (Aronsson et al., 2011; Rahimnia and Moghadasian, 2010; Towill and Christopher, 2005). A leagile process is a process which combines agile and 
lean concepts (Aronsson et al., 2011). Aronsson et al. (2011) argue that healthcare processes should be divided into sub-processes according to organizational boundaries. Furthermore, each sub-process should be standardized and be subject to either a lean or agile design depending on the characteristics of the sub-process, e.g. variability and volume.

In addition to the impact of predictability on selecting a suitable BPM approach, hospitals must decide whether to adopt a radical or incremental change approach for introducing BPM interventions. In terms of continuous improvement, studies have demonstrated that approaches such as lean, JIT and TQM are applicable in a healthcare setting due to high volumes and repetitive tasks, e.g. (Chen et al., 2004; Jarrett, 1998; Persona et al., 2008; Souza, 2009). Similarly, Kumar et al. argue that the more radical BPR approach is suitable for a healthcare setting due to the tangibility of items, high volumes and task repetition (Kumar, Ozdamar, et al., 2008). Thus, the same arguments seem to apply for both incremental and radical change approaches. Furthermore, implementing quality management through both continuous improvement and BPR can lead to reduced operating costs and waiting time and an improved organizational structure in hospitals (Chow-Chua and Goh, 2000).

This literature review shows that although an agile approach is better at managing process variability, most literature focuses on lean rather than agility (Rahimnia and Moghadasian, 2010). Furthermore, introducing a leagile approach in hospitals could support hospitals in achieving both responsive and efficient processes (Aronsson et al., 2011), although literature on this topic too is scarce. However, practitioners need guidelines for how to select a suitable BPM intervention and ensure successful implementation (van Lent et al., 2012). Thus, it seems that literature does not necessarily treat the topics needed to address the specific challenges of a healthcare 
setting. Furthermore, literature should aim to close the gap between research needs and the needs of practitioners by providing guidelines for selecting a suitable BPM approach. More research is therefore needed on the application of BPM in healthcare, particularly when and how it should be applied. This paper proposes a set of impact factors that supports decision makers in designing logistics processes which accommodate the needs of a hospital.

Pan and Pokharel (2007) argue that to understand logistics activities in hospitals, it is necessary to determine the use of information and communication technologies (ICTs) and barriers to ICT adoption. This study identifies factors determining technology adoption specifically for a healthcare logistics setting. The study combines the TOE framework with BPM theory, thus adding a process construct to the TOE framework. The TOE framework ensures that necessary technology adoption aspects are considered. BPM theory, in turn, ensures the success of the process in which the technology is adopted.

The difference between the BPM aspect and the TOE framework lies in the environment of the TOE framework and the process dimension of the BPM perspective. This paper has argued that to assess a technology, the process flow aspect needs to be considered. Conversely, from a BPM perspective, the environment needs to be considered because of the need to understand under which conditions the flow operates. E.g. there may be governmental requirements in terms of tracking items in the healthcare supply chain to reduce counterfeiting (Bendavid et al., 2012; Chircu et al., 2014). Furthermore, external pressure to ensure patient safety can lead to safety mechanisms in the form of RFID and barcodes in the process (Anand and Wamba, 2013; Bendavid et al., 2012). Finally, improved lead times and treatments may encourage patients to seek treatment in particular hospitals, and governments can apply 
pressure to measure and benchmark performance. As an example, in the UK, hospital benchmarking allowed for nationwide comparisons of hospitals, although it has been seriously contested whether this type of benchmarking actually encourages best practice (Northcott and Llewellyn, 2005).

\section{Method}

Research objectives, research design, data collection and data analysis are presented in the following.

\section{Research objectives}

The research objectives detail how the research questions are answered. To answer RQ1, challenges in healthcare logistics and reasons behind implementing changes in healthcare logistics were identified. The identified challenges and reasons for implementing technological instances were synthesized to encapsulate the factors impacting the decision to implement these technological instances. Thus, using the impact factors in a decision process will reflect factors already used in a decision process and additionally address challenges to improve process performance and reach organizational goals (Locke and Latham, 2002; VandeWalle et al., 2001). To answer RQ2, differences in perceived importance of the identified impact factors were established and compared to differences in process design, i.e. a cross-case analysis (Benbasat et al., 1987; Eisenhardt, 1989; Yin, 1994).

\section{Research design}

A case study research design was chosen because it provides rich data and enables a deep understanding of a phenomenon (Meredith, 1998; Yin, 2014). The investigated phenomenon is the improvement of healthcare logistics processes and the unit of 
analysis is the bed logistics process. Both quantitative and qualitative methods can be applied in case study research to understand a phenomenon (Meredith, 1998). In this study, both qualitative and quantitative data is collected and analyzed.

The investigated multiple case study consists of five hospitals located in the capital region of Denmark. The number of case studies is consistent with Eisenhardt, who suggests investigating four to ten cases (Eisenhardt, 1989). The case hospitals were chosen because they are located within the same hospital region and represent different hospital sizes and levels of technology adoption.

Although the rigor of case study research has been contested, case research can produce valid findings in itself without the need for further testing through alternative methods (Ketokivi and Choi, 2014). There is a need for case study research to advance the field of operations management (McCutcheon and Meredith, 1993) and an increase in such studies has been observed in recent years (Barratt et al., 2011). The rigor of case study research has been demonstrated for building supply chain management and logistics theory, e.g. (Ellram, 1996; Stuart et al., 2002). However, the quality aspects of case research within logistics and supply chain management are often poorly described. To properly assess the quality of case research, Pedrosa et al. (2012) propose the use of three quality criteria: transferability, truth-value and traceability. Each of these quality aspects is described later in the Method section.

Ketokivi and Choi (2014) emphasize the importance of a theoretical orientation in case research. They argue that case research can generate, test or elaborate theory. Theory elaboration focuses on contextualizing a general theory. Thus, case studies can enable theory refinement and extension (Voss et al., 2016). This study elaborates and refines the TOE framework by identifying underlying factors relating to the TOE constructs and extends the TOE framework in terms of the added BPM aspect. 


\section{Data collection}

Data was collected over a seven month period. The case study hospitals were chosen because they differ in size and specialization whilst being located within the same region. Hospital 1 served as a pilot for data gathering in the other hospitals (see hospital overview in Table 1). Both qualitative and quantitative data was collected. Data was collected mainly through interviews and observations and was carried out in three stages: 1) a preliminary stage, 2) a round of semi-structured interviews, and 3) a round of structured interviews to validate the results. The interviewees were chosen based on their knowledge of the bed logistics process and their involvement in a technology adoption and process improvement decision. In addition, different types of documents were gathered as background information from Hospital 1.

(1) The preliminary stage. The preliminary stage was carried out in Hospital 1, serving as a pilot study, with twelve open interviews and four process observation sessions. Interviews were conducted with managers in the logistics department involved in the bed logistics process. Furthermore, clinical staff and employees with knowledge of data, technologies and improvement initiatives in the bed logistics process were interviewed. In eight of the interviews, managers were interviewed and in four of the interviews employees were interviewed. The observations were direct observations of each step of the bed logistics process with some interaction with the people involved. Furthermore, documents were collected that provided an overview of beds in the outpatient clinic, a standard operating procedure for handling beds, data on the number of dirty beds collected and cleaned, and admission and discharge data. The purpose of data collection in the preliminary stage was to learn about the bed logistics process, the challenges in the process, and any improvement potential. Although the nature of data gathering in Hospital 1 resembled a pilot, data gathering was extensive enough to match 
the quality of data gathered in the other hospitals and was therefore included in the final study.

(2) Semi-structured interviews. A round of semi-structured interviews was then carried out with a manager at each of the other four hospitals. These managers were responsible for the cleaning of beds. Furthermore, the bed logistics process at each of these four hospitals was observed, focusing on the part of the process for cleaning and for transporting beds. The data collected at this stage was then analyzed and a list of impact factors identified.

(3) Structured interview validation. A round of structured interviews followed with a manager from each of the five case study hospitals. The impact factors identified in the first two data collection stages were presented in the structured interviews. Respondents were then asked to rank the identified impact factors on a scale from 0-10 according to importance for improving healthcare logistics processes. Interview guides were used for the interviews with questions related to the research questions and objectives. Additional guidelines were used to guide the observations. The interviews lasted between $1 / 2-1 \frac{1}{2}$ hours and the observations lasted $1-2$ hours. The interview guide for the structured interviews can be found in appendix.

\section{Analysis}

Based on the reviewed literature, a conceptual framework for data analysis is developed combining technology adoption theory with BPM theory. Specifically, the conceptual framework combines the TOE framework with the dimensions of success criteria for BPM. Figure 1 illustrates the developed conceptual framework. The framework is used to code the qualitative data collected in the case study hospitals. By coding data according to the four constructs, i.e. healthcare environment, technology, organizational 
structure and process flow, factors impacting the decision to adopt technologies in the bed logistics process were identified.

[FIGURE 1 NEAR HERE]

The analysis follows the sequence of the research objectives. Challenges, implemented technologies, and reasons for implementation were identified through coding of interview and observational data (Corbin and Strauss, 2015; Miles et al., 2014). Data was coded to identify factors impacting the decision to implement changes in a process. Each identified factor was ranked according to importance for improving healthcare logistics processes. In the structured interviews, the impact factors were ranked by letting respondents assign values on a $0-10$ scale; 0 being of no importance and 10 being of extreme importance to the improvement of processes.

\section{Data validity and reliability}

To improve the validity of the results, a multiple case study was chosen as research design (Eisenhardt, 1989; Eisenhardt and Graebner, 2007; Yin, 2014). The three quality criteria proposed by Pedrosa et al. (2012) to assess the quality of case research are described in the following. First, transferability refers to the extent to which the findings of a study apply to other contexts. Transferability is ensured by stating the theoretical aim in the Introduction, describing the unit of analysis, i.e. the bed logistics process, and justifying the case selection as done in the Research design section of the Method. Second, truth-value refers to the conformance between the reality of the informants' context and the reality presented by the researcher. Truth-value is ensured through a careful description of the data analysis process in the Results, including the coding process. Third, traceability refers to documenting data and the research process. To increase reliability, a case study protocol was used to guide data collection (Yin, 1994). 
Interview guides, observation guides, and purpose of data collection were included in the protocol. Respondent validation was used to further improve the validity of the study (Yin, 2014). Furthermore, a description and overview of informant selection is provided. Transparency of the reasoning in the conducted research is vital for the rigor of case research (Ketokivi and Choi, 2014). Thus, the chain of evidence linking data, analysis and results is found in the Results section and is displayed in table form (Table 2) as promoted by several authors (Eisenhardt and Graebner, 2007; Miles et al., 2014; Voss et al., 2002).

Multiple data sources were used to enable triangulation of data, hence increasing reliability and providing stronger evidence to substantiate the identified constructs (Benbasat et al., 1987; Eisenhardt, 1989; Voss et al., 2002), i.e. impact factors. Examples of data triangulation were found where different data sources support the same argument. Conversely, some statements were found to contradict other sources of evidence; e.g. compared to what had been observed or what had been stated in another interview.

Case study research is situationally grounded whilst seeking a sense of generalizability. This ensures methodologically rigorous and practically relevant research (Ketokivi and Choi, 2014). This study is situationally grounded in bed logistics, but seeks generalizability for hospital logistics processes. The study targets practitioners in healthcare management, particularly managers in healthcare logistics.

\section{Results}

Impact factors are identified based on case study data and ranked. In this section, case study data is analyzed using the conceptual framework developed for this study. Factors influencing the decision to adopt technological innovations are identified for each of the constructs in the framework. The impact factors are then ranked according to the 
importance in a technology adoption decision.

\section{Identifying impact factors related to the healthcare environment}

Three of the five case hospitals have a 24 hour emergency department whereas the other two hospitals provide an emergency clinic with limited opening hours. Table 1 provides an overview of the hospitals.

\section{[TABLE 1 NEAR HERE]}

The environmental context of the TOE framework relates to the industry, competitors and government. The Danish healthcare system is mainly government funded and the administration of hospitals is divided into five regions. The five case hospitals are all located within the capital region and differ in size and specialization. Because the hospitals are publicly funded and offer different specializations, the hospitals do not compete in the same way as in the private sector. In terms of governmental influence, the hospitals are subject to a yearly 2 per cent productivity goal (Astman et al., 2016). The productivity requirement has increased the pressure on hospitals to become more efficient and effective. Factors related to increasing the efficiency of hospitals have been categorized as process flow indicators because of a better thematic match, although the motivation relates to the environmental context.

As public entities, the hospitals must follow certain laws and guidelines. In terms of bed cleanliness, i.e. output quality, all of the hospitals had encountered quality issues with the cleanliness of hospital beds. Some hospitals had therefore added process steps to ensure cleanliness. Hospital 4 claimed not to have quality issues anymore due to major quality improvement efforts:

\footnotetext{
Compared to the other hospitals, we don't really have any quality issues, but it's something that is very important to us. The wards used to fail hygiene checks, so
} 
we introduced check lists for the beds before cleaning. If the bed fails the check, it is sent to repairs. Also, every bed has an ID and we manually register whether the bed has been cleaned manually or in a machine.

Furthermore, environmental goals, i.e. environmental consideration and laws regarding employment, e.g. employee work conditions must be considered. The importance of environmental considerations is supported by the following statement of a manager from Hospital 2:

The bed washing machine we chose is very environmentally friendly and only uses 10-12 liters of water per wash. By comparison, one of the other hospitals uses 200 liters of water per wash... some even say 800 liters per wash!

The importance of employee work conditions is exemplified by a quote from a Hospital 3 manager:

\begin{abstract}
This year we are establishing a new area for cleaning and making beds, which will run on tracks, have improved indoor climate, cranes will be used for heavy lifting and there will be more natural light in the room. Currently, the employees must walk outside every hour due to no natural light and poor indoor climate. The new facility will greatly improve the work conditions for the employees.
\end{abstract}

Factors relating to efficiency and employee work conditions better suit the process flow and organizational structure contexts. Thus, from a bed logistics perspective, it may be necessary to view the environmental context somewhat differently. In this study, the environment is therefore viewed from a systems point of view as anything that enters, exits or somehow influences the system, i.e. the bed logistics process, from the outside. Thus, in addition to output quality, future proofing, security of supply and impact on related processes were identified as impact factors relating to the healthcare environment. In terms of future proofing, this was imperative for the choice of bed washing machine at Hospital 2: 
There were several possible solutions in play, but one of the most important reasons for choosing this solution was that it is simple for the employees to operate and the machine is easy to repair, it is not necessary to split the whole thing apart.

The challenges of security of supply was corroborated by several statements, e.g. Hospital 3: "It is a challenge that there are not always enough pillows and blankets", and Hospital 4: "It can be a challenge that there are sometimes not enough beds available for the patients". Finally, impact on related processes can be either of a positive or negative nature; e.g. a negative impact of increased workloads for other processes, or a positive impact of using washing machines for other items such as assistive aids. As a manager from Hospital 5 notes:

We have started to use the washing machines to clean other things than beds, for example assistive aids. We have even had a cart developed especially for the assistive aids to be able to wash them in the machines.

\section{Identifying impact factors related to process flow}

The bed logistics process starts with the patient being admitted to the hospital and placed in a bed. During hospitalization, the patient is transported in a bed by transporters to and from treatments. Furthermore, the bed is cleaned in the ward by the cleaning department during their daily cleaning routine. When the patient is discharged, the dirty bed is transported to a central bed cleaning area by a transporter and cleaned by a central bed cleaning team. In some hospitals, beds are cleaned manually, in others they are cleaned automatically using special washing machines. One of the hospitals distinguishes between 'slightly dirty' and 'dirty' beds; slightly dirty beds are cleaned manually using disinfectant wipes and dirty beds are cleaned in a washing machine. This study is delimited to the part of the bed logistics process from the bed being delivered to the patient until the bed is delivered to a new patient. However, patient transport is not part of this study. 
The identified impact factors relating to the efficiency and effectiveness of the process flow are lead time, risk of mistakes, consistency, value-added time and unnecessary process. Furthermore, risk of mistakes and consistency both imply a quality aspect. In terms of lead time, a manager from Hospital 5 had the following remark:

We invested in a crane to improve the work conditions of our employees. The challenge is that the crane takes too long and so the employees don't want to use it because it's too slow.

Risk of mistakes was an issue due to a lack of process knowledge and perhaps even disregard among certain employee groups as pointed out in Hospital 1:

Beds for pick-up should be handed over in a certain way, but the nurses don't always follow procedure. Sometimes we're in doubt about whether the bed is actually supposed to be picked up or not. And if oxygen bottles and other things are left in the bed, it can cause technical problems at the conveyor belt and stop it.

Further quotes supporting the identified impact factors can be found in Table 2 .

\section{Identifying impact factors related to organizational structure}

The organizational structure relates to aspects such as scope, size, and managerial structure. The bed logistics process involves several different organizational units: bed cleaning staff, general cleaning staff, transporters and nurses. The large number of organizational units involved in the bed logistics process makes the process fragmented and requires collaboration between several staff groups. This fragmentation increases the risk of mistakes in the process, i.e. a process related factor, and emphasizes the significance of competence shifts, i.e. handovers, and competence match, i.e. ensuring the right skills and behavior. E.g. as noted by a transporter at Hospital 1: 
Each floor leaves the beds for pick-up differently, so you have to learn how they do it in each floor so you don't make a mistake.

The work conditions for employees have improved greatly over the years. The centralized bed cleaning provides better ergonomic work conditions and some hospitals have introduced equipment for loading and unloading mattresses. One hospital implemented a monorail to ease transport to a separate bed cleaning facility and to improve the ergonomic position for bed cleaning staff. Another hospital introduced cranes for lifting mattresses:

\begin{abstract}
We invested in a crane to improve the work conditions of our employees. The challenge is that the crane takes too long and so the employees don't want to use it because it's too slow.
\end{abstract}

A main challenge in the bed logistics process is employee engagement, particularly employee absenteeism. Cleaning tasks and patient transport are considered dull, repetitive tasks that are physically demanding, leading to high rates of absenteeism. Another challenge relating to employee engagement is low staff retention rates:

There are over 80 ways of cleaning a room and the employees need to learn the right way under for circumstance. We pay for extensive training of the employees and then they go off to a better paid job in the private sector.

This lack of continuity in the staff base poses challenges for the quality of cleaning as mentioned by the head of the cleaning department at Hospital 1:

\footnotetext{
The quality of cleaning depends greatly on the person doing it...especially for weekend staff and the use of temps during vacation season, but we are trying to solve the issue through training.
} 


\section{Identifying impact factors related to technology}

The technology context refers to relevant technologies which are in use and available in the market. The hospitals differ in the extent of technology adoption in the bed logistics process. The degree of automation therefore differs greatly for the hospitals and influences the process, e.g. in terms of output quality, the elimination of unnecessary processes and employee work conditions. The identified technologies include washing machines for bed washing, equipment to load and unload mattresses when washing beds, a monorail for bed transport, and barcodes and RFIDs for tagging beds. The parentheses in Table 1 indicate that the technology had been installed but was not used in everyday operations. This was due to either 1) the implementation had failed, 2) the technology had only been tested, or 3) further investments were needed to fully operate. The attempted implementation of a crane in hospital 3 failed because the crane could not endure water, and the crane in hospital 5 failed because employees refused to use it due to prolonged processing times. Hospital 1 had barcodes attached to all of the beds for repair purposes but lacked the software to enable bed management. RFID was tested at hospital 1 and 4, but had not been implemented due to political reasons. One important difference between barcodes and RFID is the degree of automation, i.e. RFID technology can automatically capture data whereas barcodes need manual intervention.

Data availability in the bed logistics processes is scarce. However, technologies such as RFID can increase data availability and consequently enable traceability and information management to improve process flows. Two managers at Hospital 1 elaborate on these two factors:

\footnotetext{
Not a lot of data exists around bed logistics...we have started to count the number of beds cleaned using an electronic device, but it does not register the progression during the day, it just gives us a total...so we write down three times a day what
} 
the count is. And this is only for normal beds, children's beds we still count manually.

Seventeen impact factors were identified. Table 2 provides transparency on how the impact factors were derived from data.

[TABLE 2 NEAR HERE]

Table 3 summarizes the identified impact factors and how they relate to the constructs Healthcare environment, Technology, Process flow and Organizational structure.

[Table 3 near here]

\section{Ranking the identified impact factors}

Table 4 provides an overview of how the hospitals have weighted each of the identified impact factors. The table is sorted in descending order according to the average weight $(\mu)$ and includes the standard deviation $(\sigma)$ for each impact factor. The association of impact factors to the constructs Healthcare environment $(\mathrm{H})$, Technology $(\mathrm{T})$, Process flow $(\mathrm{P})$ and Organizational structure $(\mathrm{O})$ is indicated in the table.

[TABLE 4 NEAR HERE]

A few comments on the validity of the results in Table 4 are necessary. First, Hospital 1 weighted the decision parameters more nuanced and lower than the other hospitals. This could reflect either a different interpretation of the scale or simply a lower perceived importance of the decision criteria. Furthermore, all hospitals seem to agree that output quality is of high importance. Hospital 4 had diligently addressed their quality issues through different initiatives, thus did not assign a high weight to output quality.

However, the fact that the hospital had invested substantial efforts to reach the current 
level of quality indicates that output quality is indeed important and that the weighting does not reflect the manager's actual view. The discrepancy is evident in the following statement from the manager responsible for bed logistics at the hospital:

Compared to the other hospitals, we don't really have any quality issues, but it's something that is very important to us. The wards used to fail hygiene checks, so we introduced check lists for the beds before cleaning. If the bed fails the check, it is sent to repairs. Also, every bed has an ID and we manually register whether the bed has been cleaned manually or in a machine.

The case study hospitals have different levels of technology adoption in the bed logistics process (see Table 1). To ensure that the weighted importance of impact factors is not merely a product of technology adoption levels in the organization, the hospitals were grouped in Table 4 according to their level of technology adoption in the bed logistics process. Hospital 3 uses no technologies in daily operations whereas Hospital 2 has adopted three types of technologies. The use of technology in the bed logistics process at Hospital 1, 4 and 5 is somewhere in the middle. Table 4 shows that the degree of automation is the only impact factor that shows a consistent pattern in relation to technology adoption. For the hospitals with either high or low technology adoption, the degree of automation is considered of high importance. For the hospitals with medium technology adoption, the importance was considered slightly lower.

In summary, most hospitals agreed that the impact factors identified in the interviews are important for improving healthcare logistics processes as none of them have received low average scores. Furthermore, apart from degree of automation, the importance of the impact factors did not seem to depend on the level of technology adoption. 
High ranking impact factors

The highest ranking impact factors are also the factors that exhibit the most agreement amongst respondents, i.e. low standard deviation $(\sigma)$. The highest ranking impact factors relate to quality, employee work conditions and employee engagement. The identified factors risk of mistakes, consistency and output quality relate to quality. Output quality is included here, as the ranking does not reflect actual perceived importance, particularly regarding Hospital 4 which had introduced additional steps to ensure the cleanliness of beds upon patient discharge. Although hospitals have introduced several measures to address the challenges related to quality, employee work conditions and employee engagement, employee engagement in particular continues to be a significant challenge.

Impact factors with low consensus

The impact factors with low consensus, i.e. high standard deviations, are incidentally also the lowest ranking impact factors (see Table 4). The lowest ranking factors are competence match, competence shifts, traceability and unnecessary process. Hospital 1, 2 and 3 do not see competence match as an important impact factor. Interestingly, Hospital 2 is the same hospital that stressed the importance of a simple washing machine solution that is easy for the employees to use. Furthermore, the Hospital 1 case study provides supporting evidence that competence match is imperative in ensuring correct handovers, i.e. competence shifts. Hospital 1 and 2 consider competence shifts of low importance. However, Hospital 1 has experienced several challenges when it comes to handovers as items are erroneously left in beds, disrupting the automated transport and causing downtime and a need for maintenance as noted by a transporter: 
Beds for pick-up should be handed over in a certain way, but the nurses don't always follow procedure. Sometimes we're in doubt about whether the bed is actually supposed to be picked up or not. And if oxygen bottles and other things are left in the bed, it can cause technical problems at the conveyor belt and stop it.

It would seem that the manager is either not aware of this challenge or simply does not view it as an important issue.

Technologies can be used to register handovers in the process and ensure traceability. Hospital 2 is the only hospital that does not view traceability as an important decision criterion. However, Hospital 2 is one of the hospitals that have actually invested in barcode technology for traceability in the process. Thus, there seems to be some inconsistency between the use of barcodes to ensure traceability and the statement that traceability is not important.

All hospitals stated that the financial aspect of investing in a potential technology should be considered. There seems to be a discrepancy between the perceived low importance of an unnecessary process and a strong emphasis on the financial aspect. This indicates that some of the managers may not want to admit to cutting resources. Conversely, as one of the bed cleaning managers pointed out:

Automation is important for improving efficiency. However, we must also think of the people working in these jobs - it will be difficult for them to find other jobs. I believe in future solutions that include both automation and people.

Thus, there seems to be a sense of responsibility from management to ensure jobs for these employees. Another manager raised this point and referred to their social responsibility.

In summary, for the impact factors with low consensus, the perceived low importance of an impact factor often did not match with other statements or past behavior and should have been assigned higher values. 


\section{Discussion}

The benefits realized from a technology differ between companies (Xie et al., 2016); what is right for one company may not be right for others. The state of a process and the improvement potential of a process affect the benefits that can be realized from introducing a new technology. Moreover, depending on whether a radical or incremental process approach is applied may limit the possibilities of introducing a technology that would cause radically different processes. Thus, most investments in a company require a business case to justify the investment, including financial and operational effects. To better understand and predict technology adoption, a technology adoption framework should reflect this reality of organizations and include the BPM dimension to consider the operational effects of a technology. Conversely, BPM benefits from a technological perspective as technologies can affect both process design (Hung, 2006; Trkman, 2010) and process efficiency (Voss, 1988).

RQ1 implies a relationship between processes and technologies. A conceptual framework was developed based on the TOE framework and the success factors of BPM to analyze the case study data. The framework consists of four constructs: healthcare environment, technology, organizational structure and process flow. Combining the TOE and BPM framework suggests a relationship between the four constructs.

Examining the TOE framework, the technological and environmental aspects of the TOE framework constitute external factors, whereas the organizational aspect is internal to the organization. Adding a BPM perspective provides an additional internal dimension to the framework and creates a framework that is even more pertinent to a specific company or hospital, also providing a balance between external and internal constructs. 
A set of 17 impact factors was identified. Apart from the degree of automation, the study shows that the impact factors as decision criteria do not depend on the existing level of technology adoption. The identified impact factors each relate to one of the constructs healthcare environment, technology, process flow and organizational structure. Other studies have in a similar fashion identified factors inherent to the TOE framework for the adoption of certain technologies within a healthcare setting. E.g. performance gap, market uncertainty, perceived benefits, technology knowledge and vendor pressure influence RFID adoption in healthcare (Lee and Shim, 2007). Furthermore, factors relating to perceived benefits, costs, IT readiness, action/interaction in the RFID adoption process and reactions to the RFID application affect RFID adoption in healthcare (Cao et al., 2014). Moreover, hospital size, adequate resources, vendor support and government policy have been identified as significant factors determining e-signature adoption in healthcare (Chang et al., 2007). Hu et al. (2000) identify collective attitude of medical staff, perceived service risks and perceived ease of use as significant factors influencing technology adoption.

This study suggests a number of new factors underlying the TOE framework for a healthcare logistics setting. For the technology construct, impact on related processes and future proofing had not been identified in other studies as impact factors. For the organizational structure construct, others have described the importance of human factors, e.g. attitudes and perceptions (Chang et al., 2007; Hu et al., 2000). The novelty of the factors identified in this study lies in the importance of competence shifts, i.e. handovers, competence match, employee engagement and work conditions. For the healthcare environment construct, environmental considerations and degree of automation constitute new constructs identified in this study. Finally, the additional process flow construct consists of five factors: lead time, value-added time, risk of 
mistakes, consistency and unnecessary process. I.e. these factors have not been identified previously in TOE literature as they do not fit the original TOE constructs. However, the factors share similarities with two of the healthcare supply chain performance dimensions suggested by Lega et al. (2012), namely delivery performance and time to deliver. Furthermore, the importance of flexibility to assess healthcare supply chain performance as proposed by Lega et al. (2012) suggests that a process perspective is relevant in assessing supply chain solutions. Given that demand variability calls for the application of agile process strategies in healthcare as noted in the literature review (Aronsson et al., 2011), flexibility can help achieve agile processes and supply chains to cope with demand variability.

Compared to the factors identified by other researchers, the factors identified in this study focus more on the operational and quality impact of a technology in addition to the interdependence between factors. Furthermore, this study provides a more nuanced framework for explaining technology adoption in healthcare logistics by suggesting additional factors relating to each of the four constructs.

To answer RQ2, the impact factors were ranked. The factors perceived as most important for adopting technologies in healthcare logistics processes relate to quality, employee work conditions and employee engagement. Improvement of these aspects should therefore be incorporated in the process design. Relating to extant literature, the quality concept is inherent to BPM, which is rooted in TQM (Hung, 2006; Zairi and Sinclair, 1995). On the point of employee work conditions, poor ergonomics can lead to worker injuries and has lately received more attention in literature, e.g. (Andriolo et al., 2016; Grosse et al., 2015; Keller and Ozment, 2009). Both poor employee work conditions and low employee engagement can lead to injuries, high absenteeism and high turnover rates, which in turn can be costly to the employer. However, 
incorporating human factors in an operating model, e.g. by involving workers in the process design, can improve the outcome for both employees and production (Grosse et al., 2015; Guimarães et al., 2015). Furthermore, employee involvement is vital to the success of BPM efforts (Hung, 2006). Thus, the findings of this study align with other streams of literature. The consistency between the identified impact factors across the five case studies and literature strengthens the validity and generalizability of the results, suggesting that the impact factors apply to other hospital settings and potentially other industries.

The impact factors with least consensus regarding the importance to the redesign of healthcare logistics processes through technology adoption are competence shifts, competence match, traceability and unnecessary processes. Competence shifts and competence match in particular are viewed differently and do not seem to receive the attention they deserve. Similarly, a study by Keller and Ozment shows that logistics managers often do not focus on building employee knowledge and driving employee success (Keller and Ozment, 2009). Moreover, too many competence shifts or handoffs lead to inefficiencies and inevitable errors and misunderstandings in a process (Parnaby and Towill, 2009). However, training of both clinical and support staff to achieve the right competence match can reduce errors and ensure correct handoffs, i.e. improve quality. Training is therefore an important enabler of the successful redesign of processes (Ho et al., 1999; Hung, 2006; Trkman, 2010).

Traceability can support competence shifts and competence match by ensuring visibility in a process and accountability for each process step and handover. Closely related to traceability is the degree of automation, which can support traceability. Finally, unnecessary processes in an organization correspond to waste in a BPM context and should be eliminated (Hammer, 1990; Hammer and Champy, 1993; Womack and 
Jones, 2003). Except for competence shifts and competence match, the case study hospitals seem to consider the low consensus impact factors more than they let on. However, hospitals could benefit from paying more attention to competence shifts and competence match both within and outside of the logistics organization. The lack of respect and recognition of the importance of logistics activities found in the case study is an example of how logistics and the benefit of logistics need to be marketed to the rest of the organization to fully reap the potential of logistics services (Ralston et al., 2013).

In addition to identifying and ranking the impact factors, relations between the impact factors have been identified. First, combining the TOE framework and BPM perspective indicates a relationship between the four constructs technology, environment, organizational structure and process flow. The novelty lies in the combination of all four constructs and in the new relation between the environment and the process flow. Thus, the environment affects how the process is designed, e.g. if a sterile environment is needed. Conversely, the process affects the environment, e.g. in terms of customers or patients and competitors. Second, the identified impact factors underlying each construct are inadvertently linked according to the links between the constructs. Third, antecedents of quality were identified from the impact factors relating to organizational structure; competence shifts increases risk of mistakes, competence match decreases risk of mistakes and increases output quality, and employee engagement increases output quality. Furthermore, degree of automation was found to increase output quality, eliminate unnecessary processes, improve employee work conditions, and enable traceability and information management.

Each of the four main constructs in the developed framework should be considered and balanced when making changes to a logistics process, much like 
balancing the four perspectives of the Balanced Scorecard (Kaplan and Norton, 1992).

The ranking of the impact factors indicates the weight each impact factor and subsequently each construct holds in a technology adoption decision. The impact factors could therefore be used as part of a quantitative assessment, e.g. by applying the AHP method or through a more descriptive and strategic analysis (Meredith and Suresh, 1986). AHP has been used for similar purposes such as determining process performance for different process designs (Frei and Harker, 1999), health technology assessment (Ritrovato et al., 2015), technology justification (Meredith and Suresh, 1986), and benchmarking logistics performance (Korpela and Tuominen, 1996). The decision factors could also provide areas for benchmarking process performance and ultimately identifying best practices. Thus, the prioritization of the decision factors brings attention to areas that should be improved first.

To summarize the discussion, the contribution of this study lies in the following. First, the study extends the TOE framework by combining the TOE and BPM perspectives. Second, impact factors pertinent to technology adoption in healthcare logistics are identified. Third, the level of technology adoption within a given organization does not seem to affect the importance of impact factors other than degree of automation. Fourth, differences in importance of impact factors are determined to better assess and predict technology adoption. Fifth, relations between impact factors were identified. Sixth, the impact factors provide a framework to which quantitative assessment methods can be applied to assess technologies.

\section{Conclusion}

This paper adds to the limited empirical research on technology adoption within the field of healthcare logistics. A multiple case study was conducted at five Danish hospitals and 17 factors influencing the decision to adopt technologies in a healthcare 
logistics context were identified. Furthermore, the impact factors were ranked and the most important factors identified as those relating to quality, employee work conditions and employee engagement. In the following, the scientific contribution and practical implications are explicated.

In terms of scientific contributions, the study focuses on bed logistics processes in hospitals and combines a technology adoption and BPM theoretical lens to enhance the TOE framework. A conceptual framework for technology adoption was developed consisting of the three TOE constructs and an added process flow construct from the BPM perspective. This study thereby contributes to technology adoption theory by extending and refining/elaborating the TOE framework; extension in terms of the added process flow construct and refinement/elaboration in terms of the impact factors identified for each of the four constructs in the developed conceptual framework. Thus, the conceptual framework was tested for the bed logistics process and refined through the identified impact factors. The results show that the proposed conceptual framework is applicable as a technology adoption framework and for a healthcare logistics setting. Although other studies have combined different theories with TOE, the framework developed in this study distinguishes itself from existing research by adding the process perspective. The process perspective ensures that the process in which a new technology is adopted is taken into consideration as the technology will function as an integrated part of that process. Furthermore, the developed framework has been tested for a healthcare logistics setting and for different types of technologies rather than focusing on a single technology, e.g. telemedicine (Hu et al., 2000), RFID (Cao et al., 2014) or electronic signatures (Chang et al., 2007).

In addition to identifying the impact factors for an enhanced technology adoption framework, the impact factors were ranked according to the importance in a 
technology adoption decision. Although the results show that all the identified impact factors are important to a technology adoption decision, some are more important than others. From a practical perspective, it may not be feasible to assess all the 17 impact factors. Ranking the impact factors therefore enables decision makers to focus their attention for improvement initiatives. The most important impact factors identified in this study relate to quality, employee work conditions, and employee engagement. These factors mainly relate to the process flow and organizational structure constructs of the developed framework, but also the healthcare environment construct in terms of output quality. Thus, the results of the study stress the importance of incorporating human factors in the design of healthcare logistics processes and found that human factors have implications for correct handovers and quality in the process. Furthermore, the results suggest that decision makers should focus more attention on competence match and competence shifts, i.e. handovers, as these factors have implications for the efficiency and effectiveness of the processes.

The practical implications of this study are multiple. First, the conceptual framework provides a framework for decision makers to make an informed decision concerning technology adoption in a healthcare logistics process. Second, the framework enables a quantitative assessment which can be combined with a qualitative assessment based on the impact factors. Third, the process perspective and the effects on processes of introducing a technology should be considered in adopting a potential technology. E.g. if the introduction of a technology causes extra work for other organizational units, the technology might not be worth implementing. Fourth, the identified and ranked impact factors focus the attention of decision makers to the most important aspects of a technology adoption decision specific to a healthcare logistics context, i.e. quality, employee work conditions and employee engagement. Fifth, the 
impact factors indicate where managers should focus their attention in terms of new improvement initiatives for a healthcare logistics process. E.g. antecedents of improved quality were identified, suggesting that decision makers should pay more attention to reducing competence shifts or handovers, increasing competence match to fit the task, ensure employee engagement, and increase the degree of automation. Thus, to improve quality, these antecedents should be incorporated in the process design. Sixth, understanding the factors influencing the decision to adopt a technology in a healthcare logistics setting may induce technology providers to rethink the value proposition and product design that their products will offer in the future. Consequently, the framework may support the prediction of technology adoption.

This study is subject to some limitations. First, the findings are limited to a Danish setting. Second, the findings are specific to a healthcare context. Third, the findings are limited to hospitals sized up to 700 beds and would need to be validated for larger hospitals. The findings of this study are expected to be true for hospitals that operate under similar conditions, i.e. small to large public hospitals located in developed countries. However, further studies are needed to validate this. Other areas for future research include the organizational aspect; human factors in particular are sparsely researched for healthcare logistics.

\section{References}

Ajzen, I. (1985), "From intentions to actions: A theory of planned behavior", Action Control, Springer Berling Heidelberg, pp. 11-39.

Al-Riyami, A.Z., Al-Khabori, M., Al-Hadhrami, R.M., Al-Azwani, I.S., Davis, H.M., Al-Farsi, K.S., Alkindi, S.S., et al. (2014), “The pneumatic tube system does not affect complete blood count results; a validation study at a tertiary care hospital", International Journal of Laboratory Hematology, Vol. 36 No. 5, pp. 514-520.

Anand, A. and Wamba, S.F. (2013), "Business value of RFID-enabled healthcare 
transformation projects”, Business Process Management Journal, Vol. 19 No. 1, pp. 111-145.

Andriolo, A., Battini, D., Persona, A. and Sgarbossa, F. (2016), “A new bi-objective approach for including ergonomic principles into EOQ model", International Journal of Production Research, Vol. 54 No. 9, pp. 2610-2627.

Aptel, O., Pomberg, M. and Pourjalali, H. (2009), "Improving Activities of Logistics Departments in Hospitals: A Comparison of French and U.S. Hospitals", Journal of Applied Management Accounting Research, Vol. 7 No. 2, pp. 1-20.

Aptel, O. and Pourjalali, H. (2001), "Improving activities and decreasing costs of logistics in hospitals - A comparison of U.S. and French hospitals", The International Journal of Accounting, Vol. 36 No. 1, pp. 65-90.

Armistead, C., Pritchard, J.-P. and Machin, S. (1999), "Strategic Business Process Management for Organisational Effectiveness”, Long Range Planning, Vol. 32 No. 1, pp. 96-106.

Aronsson, H., Abrahamsson, M. and Spens, K. (2011), "Developing lean and agile health care supply chains", (de Vries, J.,Ed.)Supply Chain Management: An International Journal, Vol. 16 No. 3, pp. 176-183.

Astman, U., Lose, S., Andersen, S.H., Hansen, B. and Stenbæk, J. (2016,December10), "Et presset sundhedsvæsen står ved en skillevej”, Jyllands-Posten, Viby/Copenhagen, available at: http://jyllandsposten.dk/debat/breve/ECE9215654/et-presset-sundhedsvaesen-staar-ved-enskillevej/.

Attaran, M. (2003), "Information technology and business-process redesign”, Business Process Management Journal, Vol. 9 No. 4, pp. 440-458.

Bachouch, R. Ben, Guinet, A. and Hajri-Gabouj, S. (2012), “An Integer linear model for hospital bed planning", International Journal of Production Economics, Elsevier, Vol. 140 No. 2, pp. 833-843.

Bagozzi, R. (2007), “The Legacy of the Technology Acceptance Model and a Proposal for a Paradigm Shift”, Journal of the Association for Information Systems, Vol. 8 No. 4, pp. 244-254.

Baker, J. (2012), “The Technology-Organization-Environment Framework”, in 
Dwivedi, Y.K., Wade, M.R. and Schneberger, S.L. (Eds.),Information Systems Theory, Springer, New York, NY, pp. 231-245.

Banerjee, A., Mbamalu, D. and Hinchley, G. (2008), “The impact of process reengineering on patient throughput in emergency departments in the UK", International journal of emergency medicine, Vol. 1 No. 3, pp. 189-92.

Barratt, M., Choi, T.Y. and Li, M. (2011), “Qualitative case studies in operations management: Trends, research outcomes, and future research implications", Journal of Operations Management, Elsevier B.V., Vol. 29 No. 4, pp. 329-342.

Bekker, R. and Koeleman, P.M. (2011), "Scheduling admissions and reducing variability in bed demand", Health Care Management Science, Vol. 14 No. 3, pp. $237-249$.

Benbasat, I., Goldstein, D.K. and Mead, M. (1987), “The Case Research Strategy in Studies of Information Systems", MIS quarterly, Vol. 11 No. 3, pp. 369-386.

Bendavid, Y., Boeck, H. and Philippe, R. (2012), "RFID-enabled traceability system for consignment and high value products: A case study in the healthcare sector", Journal of Medical Systems, Vol. 36 No. 6, pp. 3473-3489.

Bertolini, M., Bevilacqua, M., Ciarapica, F.E. and Giacchetta, G. (2011), "Business process re-engineering in healthcare management: a case study", Business Process Management Journal, Vol. 17 No. 1, pp. 42-66.

Bloss, R. (2011), "Mobile hospital robots cure numerous logistic needs", Industrial Robot: An International Journal, Vol. 38 No. 6, pp. 567-571.

Böhme, T., Williams, S.J., Childerhouse, P., Deakins, E. and Towill, D. (2013), "Methodology challenges associated with benchmarking healthcare supply chains", Production Planning \& Control, Vol. 24 No. 10-11, pp. 1002-1014.

Cao, Q., Jones, D.R. and Sheng, H. (2014), “Contained nomadic information environments: Technology, organization, and environment influences on adoption of hospital RFID patient tracking”, Information \& Management, Vol. 51, pp. 225239.

Chan, F.T.S., Chan, M.H., Lau, H. and Ip, R.W.L. (2001), “Investment appraisal techniques for advanced manufacturing technology (AMT): a literature review", Integrated Manufacturing Systems, Vol. 12 No. 1, pp. 35-47. 
Chang, I.-C., Hwang, H.-G., Hung, M.-C., Lin, M.-H. and Yen, D.C. (2007), "Factors affecting the adoption of electronic signature: Executives' perspective of hospital information department”, Decision Support Systems, Vol. 44, pp. 350-359.

Chen, H.-K., Chen, H.-Y., Wu, H.-H. and Lin, W.-T. (2004), “TQM Implementation in a Healthcare and Pharmaceutical Logistics Organization: The Case of Zuellig Pharma in Taiwan”, Total Quality Management \& Business Excellence, Vol. 15 No. 9-10, pp. 1171-1178.

Chircu, A., Sultanow, E. and Saraswat, S.P. (2014), "Healthcare RFID In Germany: An Integrated Pharmaceutical Supply Chain Perspective", Journal of Applied Business Research, Vol. 30 No. 3, pp. 737-752.

Chow-Chua, C. and Goh, M. (2000), "Quality improvement in the healthcare industry: some evidence from Singapore", International journal of health care quality assurance, Vol. 13 No. 5, pp. 223-229.

Closs, D.J., Goldsby, T.J. and Clinton, S.R. (2006), "Information technology influences on world class logistics capability", International Journal of Physical Distribution and Logistics Management, Vol. 27 No. 1, pp. 4-17.

Corbin, J. and Strauss, A. (2015), Basics of Qualitative Research - Techniques and Procedures for Developing Grounded Theory, Sage Publications, Inc., Thousand Oaks, CA, 4thed.

Council of Supply Chain Management Professionals. (2016), "Definition of logistics management".

Davenport, T.H. and Short, J.E. (1990), “The new industrial engineering: Information Technology and business process redesign", Sloan Management Review, Vol. 31 No. 4, pp. 1-31.

Dobrzykowski, D., Deilami, V.S., Hong, P. and Kim, S.-C. (2014), “A structured analysis of operations and supply chain management research in healthcare (19822011)", International Journal of Production Economics, Elsevier, Vol. 147, pp. $514-530$.

Eisenhardt, K.M. (1989), “Building Theories from Case Study Research.”, Academy of Management Review.

Eisenhardt, K.M. and Graebner, M.E. (2007), “Theory Building from Cases: 
Opportunities and Challenges", Academy of Management Journal.

Elkhuizen, S.G., Limburg, M., Bakker, P.J.M. and Klazinga, N.S. (2006), “Evidencebased re-engineering: re-engineering the evidence: A systematic review of the literature on business process redesign (BPR) in hospital care", International Journal of Health Care Quality Assurance, Vol. 19 No. 6, pp. 477-499.

Ellram, L.M. (1996), “The use of the Case Study Method in Logistics Research”, Journal of Business Logistics, Vol. 17 No. 2, pp. 93-138.

Fishbein, M. and Ajzen, I. (1975), Belief, attitude, intention, and behavior : an introduction to theory and research, Reading, Mass.: Addison-Wesley Pub.

Frei, F.X. and Harker, P.T. (1999), "Measuring aggregate process performance using AHP”, European Journal of Operational Research, Vol. 116 No. 2, pp. 436-442.

Granlund, A. and Wiktorsson, M. (2013), “Automation in Healthcare Internal Logistics: a Case Study on Practice and Potential”, International Journal of Innovation and Technology Management, Vol. 10 No. 3, pp. 1-20.

Grosse, E.H., Glock, C.H., Jaber, M.Y. and Neumann, W.P. (2015), “Incorporating human factors in order picking planning models: framework and research opportunities", International Journal of Production Research, Vol. 53 No. 3, pp. $695-717$.

Guimarães, C.M., Carvalho, J.C. De and Maia, A. (2013), "Vendor managed inventory (VMI): evidences from lean deployment in healthcare", Strategic Outsourcing: An International Journal, Vol. 6 No. 1, pp. 8-24.

Guimarães, L.B.M. de, Anzanello, M.J., Ribeiro, J.L.D. and Saurin, T.A. (2015), "Participatory ergonomics intervention for improving human and production outcomes of a Brazilian furniture company", International Journal of Industrial Ergonomics, Vol. 49, pp. 97-107.

Hammer, M. (1990), “Reengineering Work: Don’t Automate, Obliterate”, Harvard Business Review, Vol. 68 No. 4, pp. 104-112.

Hammer, M. and Champy, J. (1993), Reengineering the Corporation: A manifesto for business revolution, HarperCollins Publishers, New York, 1sted.

Heinbuch, S.E. (1995), “A case of successful technology transfer to health care: Total 
quality materials management and just-in-time", Journal of management in medicine, Vol. 9 No. 2, pp. 48-56.

Helfert, M. (2009), "Challenges of business processes management in healthcare:

Experience in the Irish healthcare sector", Business Process Management Journal, Vol. 15 No. 6, pp. 937-952.

Hicks, C., McGovern, T., Prior, G. and Smith, I. (2015), “Applying lean principles to the design of healthcare facilities", International Journal of Production Economics, doi:10.1016/j.ijpe.2015.05.029.

Ho, S.-J.K., Chan, L. and Kidwell Jr., R.E. (1999), “The Implementation of Business Process Reengineering in American and Canadian Hospitals", Health Care Management Review, Vol. 24 No. 2, pp. 19-31.

Holm, L.B., Lurås, H. and Dahl, F. a. (2013), "Improving hospital bed utilisation through simulation and optimisation: with application to a $40 \%$ increase in patient volume in a Norwegian General Hospital.”, International journal of medical informatics, Elsevier Ireland Ltd, Vol. 82 No. 2, pp. 80-9.

Holweg, M. (2005), “The three dimensions of responsiveness", International Journal of Operations \& Production Management, Vol. 25 No. 7, pp. 603-622.

Hu, P.J.-H., Chau, P.Y.K. and Sheng, O.R.L. (2000), “Investigation of Factors Affecting Healthcare Organization's Adoption of Telemedicine Technology", Proceedings of the 33rd Hawaii International Conference on System Sciences, IEEE, Hawaii, pp. 1-10.

Hung, R.Y.-Y. (2006), "Business process management as competitive advantage: a review and empirical study", Total Quality Management \& Business Excellence, Vol. 17 No. 1, pp. 21-40.

Jarrett, P.G. (1998), "Logistics in the health care industry", International Journal of Physical Distribution \& Logistics Management, Vol. 28 No. 9/10, pp. 741-772.

Jin, M., Switzer, M. and Agirbas, G. (2008), "Six Sigma and Lean in healthcare logistics centre design and operation: a case at North Mississippi Health Services", International Journal of Six Sigma and Competitive Advantage, Vol. 4 No. 3, pp. 270-288.

Joosten, T., Bongers, I. and Janssen, R. (2009), “Application of lean thinking to health 
care: issues and observations", International Journal for Quality in Health Care, Vol. 21 No. 5, pp. 341-347.

Jørgensen, P., Jacobsen, P. and Poulsen, J.H. (2013), "Identifying the potential of changes to blood sample logistics using simulation", Scandinavian Journal of Clinical Laboratory Investigation, Vol. 73 No. 4, pp. 279-285.

Kannampallil, T.G., Schauer, G.F., Cohen, T. and Patel, V.L. (2011), “Considering complexity in healthcare systems", Journal of Biomedical Informatics, Elsevier Inc., Vol. 44 No. 6, pp. 943-947.

Kaplan, R.S. and Norton, D.P. (1992), “The Balanced Scorecard: Measures That Drive Performance", Harvard Business Review, Vol. 70 No. 1, pp. 71-79.

Karimi, J., Somers, T.M. and Bhattacherjee, A. (2007), “The Impact of ERP Implementation on Business Process Outcomes: A Factor-Based Study”, Journal of Management Information Systems, Vol. 24 No. 1, pp. 101-134.

Keller, S.B. and Ozment, J. (2009), "Research on personnel issues published in leading logistics journals: What we know and don't know", The International Journal of Logistics Management, Vol. 20 No. 3, pp. 378-407.

Ketokivi, M. and Choi, T. (2014), "Renaissance of case research as a scientific method", Journal of Operations Management, Elsevier B.V., Vol. 32 No. 5, pp. 232-240.

Kim, S.-C., Horowitz, I., Young, K.K. and Buckley, T.A. (2000), "Flexible bed allocation and performance in the intensive care unit", Journal of Operations Management, Vol. 18 No. 4, pp. 427-443.

Kollberg, B., Dahlgaard, J.J. and Brehmer, P.-O. (2007), "Measuring lean initiatives in health care services: issues and findings", International Journal of Productivity and Performance Management, Vol. 56 No. 1, pp. 7-24.

Korpela, J. and Tuominen, M. (1996), "Benchmarking logistics performance with an application of the analytic hierarchy process", IEEE Transactions on Engineering Management, Vol. 43 No. 3, pp. 323-333.

Kumar, A., Ozdamar, L. and Ning Zhang, C. (2008), "Supply chain redesign in the healthcare industry of Singapore", Supply Chain Management: An International Journal, Vol. 13 No. 2, pp. 95-103. 
Kumar, A. and Rahman, S. (2014), "RFID-Enabled Process Reengineering of Closedloop Supply Chains in the Healthcare Industry of Singapore”, Journal of Cleaner Production, Elsevier Ltd, Vol. 85, pp. 382-394.

Kumar, S., DeGroot, R.A. and Choe, D. (2008), "Rx for smart hospital purchasing decisions: The impact of package design within US hospital supply chain”, International Journal of Physical Distribution \& Logistics Management, Vol. 38 No. 8, pp. 601-615.

Landry, S. and Philippe, R. (2004), “How Logistics Can Service Healthcare”, Supply Chain Forum: An International Journal, Vol. 5 No. 2, pp. 24-30.

Lee, C.-P. and Shim, J.P. (2007), “An exploratory study of radio frequency identification (RFID) adoption in the healthcare industry", European Journal of Information Systems, Vol. 16 No. 6, pp. 712-714.

Lee, Y., Kozar, K.A. and Larsen, K.R.T. (2003), “The Technology Acceptance Model: Past, Present, and Future", Communications of the Association for Information Systems, Vol. 12 No. 1, pp. 752-780.

Lega, F., Marsilio, M. and Villa, S. (2012), “An evaluation framework for measuring supply chain performance in the public healthcare sector: evidence from the Italian NHS”, Production Planning \& Control, Vol. 24 No. 10-11, pp. 931-947.

van Lent, W.A.M., Sanders, E.M. and van Harten, W.H. (2012), “Exploring improvements in patient logistics in Dutch hospitals with a survey", BMC Health Services Research, Vol. 12 No. 1, p. 232.

Li, L. and Benton, W.C. (2006), "Hospital technology and nurse staffing management decisions", Journal of Operations Management, Vol. 24 No. 5, pp. 676-691.

Lillrank, P., Groop, J. and Venesmaa, J. (2011), "Processes, episodes and events in health service supply chains", (de Vries, J.,Ed.)Supply Chain Management: An International Journal, Vol. 16 No. 3, pp. 194-201.

Lin, H.-F. (2014), "Understanding the determinants of electronic supply chain management system adoption: Using the technology-organization-environment framework", Technological Forecasting and Social Change, Elsevier Inc., Vol. 86, pp. 80-92.

Litvak, E., Buerhaus, P.I., Davidoff, F., Long, M.C., McManus, M.L. and Berwick, 
D.M. (2005), "Managing Unnecessary Variability in Patient Demand to Reduce Nursing Stress and Improve Patient Safety", Joint Commission Journal on Quality \& Patient Safety, Vol. 31 No. 6, pp. 330-338.

Litvak, E. and Long, M.C. (2000), “Cost and quality under managed care: Irreconcilable differences?", American Journal of Managed Care, Vol. 6 No. 3, pp. 305-312.

Liu, C.C.H., Chang, C.H., Su, M.C., Chu, H.T., Hung, S.H., Wong, J.M. and Wang, P.C. (2011), "RFID-initiated workflow control to facilitate patient safety and utilization efficiency in operation theater", Computer Methods and Programs in Biomedicine, Elsevier Ireland Ltd, Vol. 104 No. 3, pp. 435-442.

Locke, E.A. and Latham, G.P. (2002), "Building a practically useful theory of goal setting and task motivation: A 35-year odyssey", American Psychologist, Vol. 57 No. 9, pp. 705-717.

Lummus, R.R., Krumwiede, D.W. and Vokurka, R.J. (2001), “The relationship of logistics to supply chain management: developing a common industry definition", Industrial Management \& Data Systems, Vol. 101 No. 8, pp. 426-432.

Markin, R.S. (1994), “Clinical laboratory automation: concepts and designs”, Seminars in diagnostic pathology, Vol. 11 No. 4, pp. 274-281.

McCutcheon, D.M. and Meredith, J.R. (1993), "Conducting case study research in operations management”, Journal of Operations Management, Vol. 11 No. 3, pp. 239-256.

McKone-Sweet, K.E., Hamilton, P. and Willis, S.B. (2005), “The Ailing Healthcare Supply Chain: A Prescription for Change”, Journal of Supply Chain Management, Vol. 41 No. 1, pp. 4-17.

Meredith, J. (1998), "Building operations management theory through case and field research", Journal of Operations Management, Vol. 16 No. 4, pp. 441-454.

Meredith, J.R. and Suresh, N.C. (1986), "Justification techniques for advanced manufacturing technologies", International Journal of Production Research, Vol. 24 No. 5, pp. 1043-1057.

Miles, M.B., Huberman, M.A. and Saldaña, J. (2014), Qualitative Data Analysis - A Methods Sourcebook, Sage, Arizona State University. 
Narayana, S.A., Elias, A.A. and Pati, R.K. (2014), "Reverse logistics in the pharmaceuticals industry: a systemic analysis", The International Journal of Logistics Management, Vol. 25 No. 2, pp. 379-398.

Naylor, J. Ben, Naim, M.M. and Berry, D. (1999), "Leagility: integrating the lean and agile manufacturing paradigms in the total supply chain", International Journal of Production Economics, Vol. 62 No. 1, pp. 107-118.

Noon, C.E., Hankins, C.T. and Côté, M.J. (2003), "Understanding the impact of variation in the delivery of healthcare services", Journal of healthcare management / American College of Healthcare Executives.

Northcott, D. and Llewellyn, S. (2005), "Benchmarking in UK health: a gap between policy and practice?", Benchmarking: An International Journal, Vol. 12 No. 5, pp. 419-435.

OECD. (2015), Health at a Glance 2015 - OECD Indicators, doi:http://dx.doi.org/10.1787/health_glance-2015-en.

Oliveira, T. and Martins, M.F. (2011), "Literature Review of Information Technology Adoption Models at Firm Level”, Electronic Journal of Information Systems Evaluation, Vol. 14 No. 1, pp. 110-121.

Pan, Z.X. (Thomas) and Pokharel, S. (2007), "Logistics in hospitals: a case study of some Singapore hospitals", Leadership in Health Services, Vol. 20 No. 3, pp. 195207.

Parnaby, J. and Towill, D.R. (2009), "Engineering cellular organisation and operation for effective healthcare delivery supply chains", The International Journal of Logistics Management, Vol. 20 No. 1, pp. 5-29.

Pedrosa, A. da M., Näslund, D. and Jasmand, C. (2012), "Logistics case study based research: towards higher quality", International Journal of Physical Distribution \& Logistics Management, Vol. 42 No. 3, pp. 275-295.

Persona, A., Battini, D. and Rafele, C. (2008), "Hospital efficiency management: The just-in-time and Kanban technique", International Journal of Healthcare Technology and Management, Vol. 9 No. 4, pp. 373-391.

Pilkington, A. and Fitzgerald, R. (2006), “Operations management themes, concepts and relationships: a forward retrospective of IJOPM", International Journal of 
Operations \& Production Management, Vol. 26 No. 11, pp. 1255-1275.

Poulin, É. (2003), "Benchmarking the hospital logistics process", CMA Management, CMA Canada, Vol. 77 No. 1, pp. 20-23.

Radnor, Z.J., Holweg, M. and Waring, J. (2012), "Lean in healthcare: The unfilled promise?", Social Science and Medicine, Vol. 74 No. 3, pp. 364-371.

Rahimnia, F. and Moghadasian, M. (2010), "Supply chain leagility in professional services: how to apply decoupling point concept in healthcare delivery system", Supply Chain Management: An International Journal, Vol. 15 No. 1, pp. 80-91.

Ralston, P.M., Grawe, S.J. and Daugherty, P.J. (2013), "Logistics salience impact on logistics capabilities and performance”, The International Journal of Logistics Management, Vol. 24 No. 2, pp. 136-152.

Reyes, P.M., Li, S. and Visich, J.K. (2012), “Accessing antecedents and outcomes of RFID implementation in health care", International Journal of Production Economics, Vol. 136 No. 1, pp. 137-150.

Ritrovato, M., Faggiano, F.C., Tedesco, G. and Derrico, P. (2015), "Decision-Oriented Health Technology Assessment: One Step Forward in Supporting the DecisionMaking Process in Hospitals", Value in Health, Elsevier, Vol. 18 No. 4, pp. 505511.

Rogers, E.M. (1995), Diffusion of innovations, The Free Press, New York, 4thed.

Schmidt, R., Geisler, S. and Spreckelsen, C. (2013), "Decision support for hospital bed management using adaptable individual length of stay estimations and shared resources.", BMC medical informatics and decision making, Vol. 13 No. 3, pp. 119.

Souza, L.B. De. (2009), “Trends and approaches in lean healthcare”, Leadership in Health Services, Vol. 22 No. 2, pp. 121-139.

Spens, K. and Bask, A.H. (2002), "Developing a Framework for Supply Chain Management", The International Journal of Logistics Management, Vol. 13 No. 1, pp. $73-88$.

Stuart, I., McCutcheon, D., Handfield, R., McLachlin, R. and Samson, D. (2002), "Effective case research in operations management: A process perspective", 
Journal of Operations Management, Vol. 20 No. 5, pp. 419-433.

Tornatzky, L.G. and Fleischer, M. (1990), The Processes of Technological Innovation, Lexington Books.

Towill, D.R. and Christopher, M. (2005), "An evolutionary approach to the architecture of effective healthcare delivery systems", Journal of Health Organization and Management, Vol. 19 No. 2, pp. 130-147.

Trkman, P. (2010), "The critical success factors of business process management", International Journal of Information Management, Vol. 30 No. 2, pp. 125-134.

Utley, M., Gallivan, S., Davis, K., Daniel, P., Reeves, P. and Worrall, J. (2003), "Estimating bed requirements for an intermediate care facility", European Journal of Operational Research, Vol. 150 No. 1, pp. 92-100.

VandeWalle, D., Cron, W.L. and Slocum Jr., J.W. (2001), “The Role of Goal Orientation Following Performance Feedback", Journal of Applied Psychology, Vol. 86 No. 4, pp. 629-640.

Venkatesh, V. (2000), "Determinants of perceived ease of use: Integrating control, intrinsic motivation, and emotion into the technology acceptance model", Information Systems Research.

Venkatesh, V. and Davis, F.D. (1996), “A Model of the Antecedents of Perceived Ease of Use: Development and Test”, Decision Sciences, Vol. 27 No. 3, pp. 451-481.

Venkatesh, V. and Davis, F.D. (2000), “A theoretical extension of the Technology Acceptance Model: Four Longitudinal Field Studies”, Management Science, Vol. 46 No. 2, pp. 186-204.

Villa, S., Barbieri, M. and Lega, F. (2009), "Restructuring patient flow logistics around patient care needs: implications and practicalities from three critical cases", Health Care Management Science, Vol. 12 No. 2, pp. 155-165.

Villa, S., Prenestini, A. and Giusepi, I. (2014), "A framework to analyze hospital-wide patient flow logistics: Evidence from an Italian comparative study", Health Policy, Elsevier Ireland Ltd, Vol. 115 No. 2-3, pp. 196-205.

Volland, J., Fügener, A., Schoenfelder, J. and Brunner, J.O. (2016), "Material Logistics in Hospitals: A Literature Review", Omega, Vol. In press, 
doi:10.1016/j.omega.2016.08.004.

Voss, C., Johnson, M. and Godsell, J. (2016), “Case research”, in Karlsson, C. (Ed.),Research Methods for Operations Management, Routledge, Abingdon, Second., pp. 165-197.

Voss, C., Tsikriktsis, N. and Frohlich, M. (2002), “Case research in operations management", International Journal of Operations \& Production Management, Vol. 22 No. 2, pp. 195-219.

Voss, C.A. (1988), "Success and failure in advanced manufacturing technology", International journal of Technology Management, Vol. 3 No. 3, pp. 285-297.

Walley, P., Silvester, K. and Stein, R. (2006), "Managing variation in demand: Lessons from the UK National Health Service”, Journal of Healthcare Management, Vol. 51 No. 5, pp. 309-320.

WHO. (2010), The World Health Report - Health Systems Financing.

WHO. (2015), "WHO health Technology Assessment", available at: http://www.who.int/medical_devices/assessment/en/ (accessed 21 June 2015).

Womack, J.P. and Jones, D.T. (2003), Lean thinking : Banish waste and create wealth in Your corporation, Free Press.

Xie, Y., Breen, L., Cherrett, T., Zheng, D. and Allen, C.J. (2016), “An exploratory study of reverse exchange systems used for medical devices in the UK National Health Service (NHS)", Supply Chain Management: An International Journal, Vol. 21 No. 2, pp. 194-215.

Yasin, M.M., Zimmerer, L.W., Miller, P. and Zimmerer, T.W. (2002), “An empirical investigation of the effectiveness of contemporary managerial philosophies in a hospital operational setting”, International Journal of Health Care Quality Assurance, Vol. 15 No. 6, pp. 268-276.

Yin, R.K. (1994), Case study research - design and methods, Sage.

Yin, R.K. (2014), Case Study Research - Design and Methods, (Knight, V.,Ed.), Sage, Thousand Oaks, CA, 5thed.

Zairi, M. (1997), "Business process management: a boundaryless approach to modern competitiveness", Business Process Management Journal, Vol. 3 No. 1, pp. 64-80. 
Zairi, M. and Sinclair, D. (1995), "Business process re-engineering and process management: a survey of current practice and future trends in integrated management", Management Decision, Vol. 33 No. 3, pp. 3-16. 


\section{Appendix}

Table A1 provides an overview of the identified factors that the bed logistics responsible at each hospital was asked to rank on a 0-10 scale. The factors were identified based on the first round of interviews.

Table 1

\begin{tabular}{|c|c|c|}
\hline Decision criterion & Description & Weight (0-10) \\
\hline Lead time & Time from order to delivery. & \\
\hline Value-added time & $\%$ of lead time adding value. & \\
\hline Security of supply & $\begin{array}{l}\text { Ensuring the right amount at the right } \\
\text { time. }\end{array}$ & \\
\hline Traceability & Enabling track and trace. & \\
\hline Degree of automation & How automated is the process? & \\
\hline Information management & $\begin{array}{l}\text { The ability to collect, analyze and } \\
\text { communicate data. }\end{array}$ & \\
\hline Environmental considerations & $\begin{array}{l}\text { Sustainable use of energy, chemicals, } \\
\text { renewable materials etc. }\end{array}$ & \\
\hline Risk of mistakes & Likelihood of mistakes occurring. & \\
\hline Consistency & $\begin{array}{l}\text { Standardization of the process and process } \\
\text { output. }\end{array}$ & \\
\hline Future proofing & $\begin{array}{l}\text { Will the solution sustain in five years? Is } \\
\text { it flexible? }\end{array}$ & \\
\hline Impact on related processes & $\begin{array}{l}\text { Negative and positive impact on other } \\
\text { processes. E.g. other use for technology or } \\
\text { increased workload for others. }\end{array}$ & \\
\hline Output quality & Quality of product/service delivered. & \\
\hline Competence shift (handovers) & Number of handovers in the process. & \\
\hline Competence match & $\begin{array}{l}\text { Do the competencies of the employees } \\
\text { match the needs of the new process or is } \\
\text { training needed? }\end{array}$ & \\
\hline Unnecessary process & Can the process be avoided? & \\
\hline Employee engagement & $\begin{array}{l}\text { Is the employee motivated to perform the } \\
\text { job? Is an incentive provided? }\end{array}$ & \\
\hline Employee work conditions & $\begin{array}{l}\text { Employee safety, work load, strenuous } \\
\text { work, ergonomics, physical and } \\
\text { psychological work environment. }\end{array}$ & \\
\hline
\end{tabular}




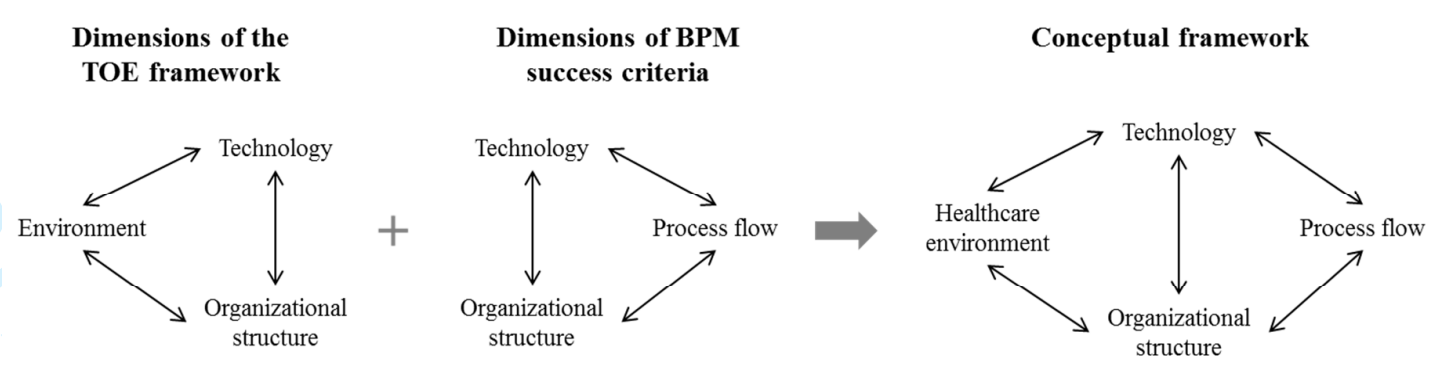

Figure 1. Developed conceptual framework for data analysis 
Table 1. Overview of case study hospitals, beds and implemented technologies

\begin{tabular}{|c|c|c|c|c|c|c|c|c|c|}
\hline \multirow[t]{2}{*}{ Hospital } & \multirow{2}{*}{$\begin{array}{c}\text { \# beds } \\
\text { occupied }\end{array}$} & \multirow{2}{*}{$\begin{array}{c}\# \text { actual } \\
\text { beds }\end{array}$} & \multirow{2}{*}{$\begin{array}{c}\text { \# beds } \\
\text { cleaned/day }\end{array}$} & \multirow[t]{2}{*}{ 24h ED? } & \multicolumn{5}{|c|}{ Implemented technologies } \\
\hline & & & & & 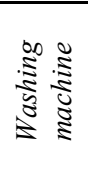 & 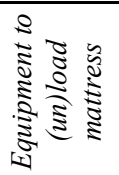 & 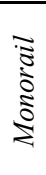 & 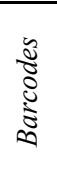 & 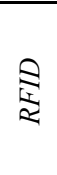 \\
\hline Hospital 1 & 700 & 1,200 & 235 & Yes & & & $\mathrm{X}$ & $(\mathrm{X})$ & $(\mathrm{X})$ \\
\hline Hospital 2 & 600 & 800 & 250 & Yes & $\mathrm{X}$ & $X$ & & $X$ & \\
\hline Hospital 3 & 500 & 1,200 & 175 & Yes & & $(\mathrm{X})$ & & & \\
\hline Hospital 4 & 300 & 560 & 110 & No & $\mathrm{X}$ & $\mathrm{X}$ & & & $(\mathrm{X})$ \\
\hline Hospital 5 & 250 & 500 & 120 & No & $X$ & $(\mathrm{X})$ & & $\mathrm{X}$ & \\
\hline
\end{tabular}


Table 2. Derived impact factors for the healthcare environment construct

\begin{tabular}{|c|c|c|c|c|c|c|c|c|c|}
\hline \multirow{2}{*}{$\begin{array}{l}\text { Impact } \\
\text { factor }\end{array}$} & \multirow{2}{*}{$\begin{array}{l}\text { Description of impact } \\
\text { factor }\end{array}$} & \multirow{2}{*}{ Challenges identified in case studies } & \multirow[t]{2}{*}{ Case study data examples (quotes) } & \multicolumn{5}{|c|}{ Technology } & \multirow{2}{*}{$\begin{array}{l}\text { Reasons for } \\
\text { implementing } \\
\text { technology identified } \\
\text { in case studies }\end{array}$} \\
\hline & & & & & 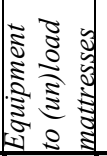 & 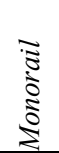 & 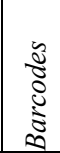 & 里 & \\
\hline $\begin{array}{l}\text { Future } \\
\text { proofing }\end{array}$ & $\begin{array}{l}\text { Ensuring that a solution } \\
\text { is viable in the long run } \\
\text { in relation to the overall } \\
\text { strategy, future capacity } \\
\text { needs, and future tech- } \\
\text { nology investments. }\end{array}$ & $\begin{array}{l}\text { The placement of the bed cleaning } \\
\text { area increases transporting time for } \\
\text { beds. The monorail transports beds to } \\
\text { the bed cleaning area, but the tact of } \\
\text { the monorail leads to inefficiencies. } \\
\text { This system is not easily replaced. }\end{array}$ & $\begin{array}{l}\mathrm{H} 2 \text { : "There were several possible solutions in play, } \\
\text { but one of the most important reasons for choosing } \\
\text { this solution was that it is simple for the employees } \\
\text { to operate and the machine is easy to repair, it is } \\
\text { not necessary to split the whole thing apart." }\end{array}$ & \multicolumn{5}{|c|}{$\mathrm{N} / \mathrm{A}$} & N/A \\
\hline $\begin{array}{l}\text { Security } \\
\text { of supply }\end{array}$ & $\begin{array}{l}\text { Ensuring that the right } \\
\text { bed and mattress is } \\
\text { available at the right } \\
\text { time. }\end{array}$ & $\begin{array}{l}\text { Difficulties exist for ensuring enough } \\
\text { clean beds and the right bed/mattress } \\
\text { for the right patient. It is not known } \\
\text { whether or not the available resources } \\
\text { will match the need of resources, } \\
\text { making it difficult to plan activities. }\end{array}$ & $\begin{array}{l}\text { H3: "It is a challenge that there are not always } \\
\text { enough pillows and blankets." } \\
\text { H4: "It can be a challenge that there are sometimes } \\
\text { not enough beds available for the patients." }\end{array}$ & \multicolumn{5}{|c|}{ N/A } & N/A \\
\hline $\begin{array}{l}\text { Impact on } \\
\text { related } \\
\text { processes }\end{array}$ & $\begin{array}{l}\text { Other processes could } \\
\text { be affected negatively } \\
\text { due to increased work } \\
\text { load. }\end{array}$ & $\begin{array}{l}\text { Increased work has incurred for } \\
\text { related processes as a consequence of } \\
\text { changes made to the bed cleaning } \\
\text { process, e.g. by centralizing bed } \\
\text { washing. }\end{array}$ & $\begin{array}{l}\text { H5: "We have started to use the washing machines } \\
\text { to clean other things than beds, for example } \\
\text { assistive aids. We have even had a cart developed } \\
\text { especially for the assistive aids to be able to wash } \\
\text { them in the machines." }\end{array}$ & $\mathrm{X}$ & & & & & $\begin{array}{l}\text { To possibly use the } \\
\text { washing machines for } \\
\text { other tasks. }\end{array}$ \\
\hline $\begin{array}{l}\text { Output } \\
\text { quality }\end{array}$ & $\begin{array}{l}\text { Quality of output, i.e. } \\
\text { the cleanliness of beds. } \\
\text { Differs from risk of } \\
\text { mistakes as output } \\
\text { quality would also } \\
\text { depend on } \\
\text { tools/machinery. }\end{array}$ & $\begin{array}{l}\text { Hospitals have experienced } \\
\text { difficulties in living up to cleaning } \\
\text { requirements due to lack of qualified } \\
\text { resources and a lack of quality } \\
\text { standards. Furthermore, measuring } \\
\text { quality is difficult and quality } \\
\text { controls are insufficient. }\end{array}$ & $\begin{array}{l}\text { H4: "Compared to the other hospitals, we don't } \\
\text { really have any quality issues, but it's something } \\
\text { that is very important to us. The wards used to fail } \\
\text { hygiene checks, so we introduced check lists for } \\
\text { the beds before cleaning. If the bed fails the check, } \\
\text { it is sent to repairs. Also, every bed has an ID and } \\
\text { we manually register whether the bed has been } \\
\text { cleaned manually or in a machine." }\end{array}$ & $\mathrm{X}$ & & & & & $\begin{array}{l}\text { To ensure consistent } \\
\text { output quality, i.e. the } \\
\text { cleanliness of all } \\
\text { cleaned beds. }\end{array}$ \\
\hline $\begin{array}{l}\text { Environ- } \\
\text { mental } \\
\text { consider- } \\
\text { ations }\end{array}$ & $\begin{array}{l}\text { Considering the use of } \\
\text { water, chemicals, } \\
\text { electricity etc. }\end{array}$ & $\begin{array}{l}\text { Excessive use of water occurs either } \\
\text { through manual or automated } \\
\text { washing, leading to environmental } \\
\text { waste. }\end{array}$ & $\begin{array}{l}\text { H2: "The bed washing machine we chose is very } \\
\text { environmentally friendly and only uses } 10-121 \text { of } \\
\text { water per wash. By comparison, one of the other } \\
\text { hospitals uses } 2001 \text { of water per wash... some } \\
\text { even say } 8001 \text { per wash!" }\end{array}$ & $\mathrm{X}$ & & & 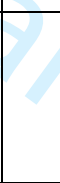 & & $\begin{array}{l}\text { To reduce the use and } \\
\text { waste of water for } \\
\text { washing bed. }\end{array}$ \\
\hline
\end{tabular}


Table 2 (continued). Derived impact factors for the technology construct

\begin{tabular}{|c|c|c|c|c|c|c|c|c|}
\hline \multirow{2}{*}{$\begin{array}{l}\text { Impact } \\
\text { factor }\end{array}$} & \multirow{2}{*}{$\begin{array}{l}\text { Description of impact } \\
\text { factor }\end{array}$} & \multirow[t]{2}{*}{ Challenges identified in case studies } & \multirow[t]{2}{*}{ Case study data examples (quotes) } & \multicolumn{4}{|l|}{ Technology } & \multirow{2}{*}{$\begin{array}{l}\text { Reasons for } \\
\text { implementing } \\
\text { technology identified } \\
\text { in case studies }\end{array}$} \\
\hline & & & & 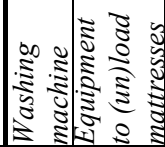 & 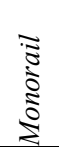 & 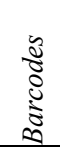 & $\underset{2}{\stackrel{1}{2}}$ & \\
\hline \multirow{2}{*}{$\begin{array}{l}\text { Degree of } \\
\text { auto- } \\
\text { mation }\end{array}$} & \multirow{2}{*}{$\begin{array}{l}\text { Enabling coordination } \\
\text { and planning of } \\
\text { activities through data } \\
\text { availability. }\end{array}$} & \multirow{2}{*}{$\begin{array}{l}\text { Lack of data availability is an issue, e.g. } \\
\text { regarding bed and mattress needs. In } \\
\text { addition, a lot of the data is manually } \\
\text { registered. This lack of data makes it } \\
\text { difficult to plan resources. }\end{array}$} & \multirow[b]{2}{*}{$\begin{array}{l}\text { H5: "Automation is important for improving } \\
\text { efficiency. However, we must also think of the } \\
\text { people working in these jobs - it will be difficult } \\
\text { for them to find other jobs. I believe in future } \\
\text { solutions that include both automation and } \\
\text { people." } \\
\text { H1: "We have started to count the number of } \\
\text { beds cleaned using an electronic device, but it } \\
\text { does not register the progression during the day, } \\
\text { it just gives us a total...so we write down three } \\
\text { times a day what the count is. And this is only for } \\
\text { normal beds, children's beds we still count } \\
\text { manually." }\end{array}$} & & $\mathrm{X}$ & & & $\begin{array}{l}\text { Use staff when human } \\
\text { attention is required. }\end{array}$ \\
\hline & & & & & & & $\mathrm{X}$ & $\begin{array}{l}\text { RFID more automated } \\
\text { than barcodes to } \\
\text { capture data. }\end{array}$ \\
\hline $\begin{array}{l}\text { Informati } \\
\text { on } \\
\text { managem } \\
\text { ent }\end{array}$ & $\mathrm{N} / \mathrm{A}$ & N/A & \multirow{2}{*}{$\begin{array}{l}\text { H1: "Not a lot of data exists around bed } \\
\text { logistics... we have started to count the number } \\
\text { of beds cleaned using an electronic device, but it } \\
\text { does not register the progression during the day, } \\
\text { it just gives us a total...so we write down three } \\
\text { times a day what the count is. And this is only for } \\
\text { normal beds, children's beds we still count } \\
\text { manually." } \\
\text { H4: "Every bed has a unique ID, and we register } \\
\text { what is washed in the machine and what is } \\
\text { washed manually." }\end{array}$} & & & $\mathrm{X}$ & $\mathrm{X}$ & $\begin{array}{l}\text { Capturing data enables } \\
\text { planning and studies } \\
\text { to improve bed flow. }\end{array}$ \\
\hline $\begin{array}{l}\text { Traceabil } \\
\text { ity }\end{array}$ & $\begin{array}{l}\text { Enabling traceability } \\
\text { and localization of } \\
\text { items in the process. }\end{array}$ & $\begin{array}{l}\text { The whereabouts of the beds is } \\
\text { unknown and data on the history of the } \\
\text { bed is not available, making it time } \\
\text { consuming and difficult to analyze how } \\
\text { to improve the utilization of beds. }\end{array}$ & & & & $\mathrm{X}$ & $\mathrm{X}$ & $\begin{array}{l}\text { Enables traceability of } \\
\text { beds, data capturing } \\
\text { and planning. }\end{array}$ \\
\hline
\end{tabular}


Table 2 (continued). Derived impact factors for the process flow construct

\begin{tabular}{|c|c|c|c|c|c|c|c|c|c|}
\hline \multirow{2}{*}{$\begin{array}{l}\text { Impact } \\
\text { factor }\end{array}$} & \multirow{2}{*}{$\begin{array}{l}\text { Description of impact } \\
\text { factor }\end{array}$} & \multirow[t]{2}{*}{ Challenges identified in case studies } & \multirow[t]{2}{*}{ Case study data examples (quotes) } & \multicolumn{5}{|c|}{ Technology } & \multirow{2}{*}{$\begin{array}{l}\text { Reasons for } \\
\text { implementing } \\
\text { technology identified } \\
\text { in case studies }\end{array}$} \\
\hline & & & & & 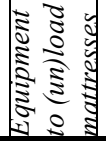 & 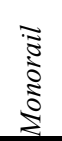 & 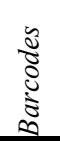 & $\underset{1}{\stackrel{1}{2}}$ & \\
\hline Lead time & $\begin{array}{l}\text { Time elapsed from a } \\
\text { significant point in time } \\
\text { until a significant end } \\
\text { time. }\end{array}$ & $\begin{array}{l}\text { Washing machines take longer but } \\
\text { provide cleaner beds, which many } \\
\text { hospitals were willing to trade off. } \\
\text { However, loading equipment for } \\
\text { mattresses failed due to employees not } \\
\text { willing to wait for equipment to finish. }\end{array}$ & $\begin{array}{l}\text { H5: "We invested in a crane to improve the work } \\
\text { conditions of our employees. The challenge is that } \\
\text { the crane takes too long and so the employees } \\
\text { don't want to use it because it's too slow." } \\
\text { H2: "It only takes } 6 \text { minutes for the machine to } \\
\text { wash three beds at a time." }\end{array}$ & $\bar{X}$ & & & & & $\begin{array}{l}\text { One of the washing } \\
\text { machines was chosen } \\
\text { because it can wash } \\
\text { several beds at a time. }\end{array}$ \\
\hline $\begin{array}{l}\text { Value- } \\
\text { added } \\
\text { time }\end{array}$ & $\begin{array}{l}\text { Time spent on process } \\
\text { steps that do not add } \\
\text { value to the patient or } \\
\text { departments. }\end{array}$ & $\begin{array}{l}\text { Non value-added time was experienced } \\
\text { in terms of excessive transport times to } \\
\text { other building, waiting time due to } \\
\text { bottlenecks, and } \\
\text { processing/cleaning. }\end{array}$ & $\begin{array}{l}\text { H1 observation: It took approximately } 16 \text { minutes } \\
\text { for a bed to be transported from the main hospital } \\
\text { building to the service building where the beds } \\
\text { were cleaned and another } 16 \text { minutes back to the } \\
\text { hospital building. }\end{array}$ & \multicolumn{5}{|l|}{$\mathrm{N} / \mathrm{A}$} & N/A \\
\hline $\begin{array}{l}\text { Risk of } \\
\text { mistakes }\end{array}$ & $\begin{array}{l}\text { The risk of making } \\
\text { mistakes in the process. } \\
\text { Risk mitigating } \\
\text { mechanisms in place. }\end{array}$ & $\begin{array}{l}\text { Mistakes mainly occur due to a lack of } \\
\text { process knowledge, e.g. nurses do not } \\
\text { leave the beds for the bed transporters } \\
\text { in the correct condition for cleaning. } \\
\text { Furthermore, there is a lack of systems } \\
\text { knowledge to perform tasks correctly. } \\
\text { Finally, incentives to perform process } \\
\text { correctly are lacking. }\end{array}$ & $\begin{array}{l}\text { H1: "Each floor leaves the beds for pick-up } \\
\text { differently, so you have to learn how they do it in } \\
\text { each floor so you don't make a mistake." } \\
\text { H1: "Beds for pick-up should be handed over in a } \\
\text { certain way, but the nurses don't always follow } \\
\text { procedure. Sometimes we're in doubt about } \\
\text { whether the bed is actually supposed to be picked } \\
\text { up or not. And if oxygen bottles and other things } \\
\text { are left in the bed, it can cause technical problems } \\
\text { at the conveyor belt and stop it." }\end{array}$ & $\mathrm{X}$ & & & & & $\begin{array}{l}\text { To avoid mistakes in } \\
\text { the process. A simple } \\
\text { solution ensures ease } \\
\text { of use for the } \\
\text { employees and makes } \\
\text { it easier to match the } \\
\text { right competencies }\end{array}$ \\
\hline $\begin{array}{l}\text { Consi- } \\
\text { stency }\end{array}$ & $\begin{array}{l}\text { The extent to which the } \\
\text { process is performed the } \\
\text { same. }\end{array}$ & $\begin{array}{l}\text { Processes are often not performed in the } \\
\text { same way because each employee has } \\
\text { their own way of doing things and there } \\
\text { are no standard operating procedures. }\end{array}$ & $\begin{array}{l}\text { H1: "Each floor leaves the beds for pick-up } \\
\text { differently, so you have to learn how they do it in } \\
\text { each floor so you don't make a mistake." } \\
\text { H1: "The quality of cleaning depends greatly on } \\
\text { the person doing it...especially for weekend staff } \\
\text { and the use of temps during vacation season, but } \\
\text { we are trying to solve the issue through training." }\end{array}$ & $\mathrm{X}$ & & & & & $\begin{array}{l}\text { To ensure consistent } \\
\text { output quality, i.e. the } \\
\text { cleanliness of all } \\
\text { cleaned bed }\end{array}$ \\
\hline $\begin{array}{l}\text { Unnece- } \\
\text { ssary } \\
\text { process }\end{array}$ & $\begin{array}{l}\text { Tasks that are } \\
\text { unnecessary and could } \\
\text { be avoided. }\end{array}$ & $\begin{array}{l}\text { Use of unnecessary resources and } \\
\text { unnecessary process steps. }\end{array}$ & $\begin{array}{l}\text { H5: "Beds that have only been used momen-tarily } \\
\text { and with no contamination risk, we clean with } \\
\text { disinfectant wipes." }\end{array}$ & $\mathrm{X}$ & & $X$ & 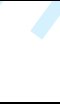 & & $\begin{array}{l}\text { To reduce the use of } \\
\text { employee resources. }\end{array}$ \\
\hline
\end{tabular}


Table 2 (continued). Derived impact factors for the organizational structure construct

\begin{tabular}{|c|c|c|c|c|c|c|c|c|c|}
\hline \multirow{2}{*}{$\begin{array}{l}\text { Impact } \\
\text { factor }\end{array}$} & \multirow{2}{*}{$\begin{array}{l}\text { Description of impact } \\
\text { factor }\end{array}$} & \multirow{2}{*}{$\begin{array}{l}\text { Challenges identified in case } \\
\text { studies }\end{array}$} & \multirow[t]{2}{*}{ Case study data examples (quotes) } & \multicolumn{5}{|c|}{ Technology } & \multirow{2}{*}{$\begin{array}{l}\text { Reasons for } \\
\text { implementing } \\
\text { technology identified } \\
\text { in case studies }\end{array}$} \\
\hline & & & & 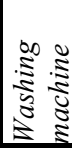 & 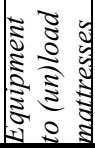 & 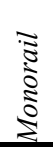 & 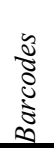 & 窟 & \\
\hline $\begin{array}{l}\text { Competence } \\
\text { shifts }\end{array}$ & $\begin{array}{l}\text { Handovers that happen } \\
\text { between resources in the } \\
\text { process. }\end{array}$ & $\begin{array}{l}\text { Handovers should be done by a } \\
\text { different personnel group to } \\
\text { avoid mistakes and rework. In } \\
\text { the current setup, mistakes occur } \\
\text { at handovers because employees } \\
\text { do not know how to hand over } \\
\text { correctly. }\end{array}$ & $\begin{array}{l}\text { H1: "Each floor leaves the beds for pick-up } \\
\text { differently, so you have to learn how they do it in } \\
\text { each floor so you don't make a mistake." } \\
\text { H1: "Beds for pick-up should be handed over in a } \\
\text { certain way, but the nurses don't always follow } \\
\text { procedure. Sometimes we're in doubt about whether } \\
\text { the bed is actually supposed to be picked up or not. } \\
\text { And if oxygen bottles and other things are left in the } \\
\text { bed, it can cause technical problems at the conveyor } \\
\text { belt and stop it." }\end{array}$ & $\mathrm{X}$ & & & & & $\begin{array}{l}\text { Simple solutions } \\
\text { ensure ease of use and } \\
\text { makes it easier to } \\
\text { match the right } \\
\text { competencies. }\end{array}$ \\
\hline $\begin{array}{l}\text { Competence } \\
\text { match }\end{array}$ & $\begin{array}{l}\text { The extent to which } \\
\text { employees have the } \\
\text { necessary competencies } \\
\text { to perform a task. }\end{array}$ & $\begin{array}{l}\text { There is a general lack of } \\
\text { systems knowledge in the } \\
\text { hospitals. Wrongful handovers } \\
\text { between departments means that } \\
\text { beds are not handed over } \\
\text { correctly. }\end{array}$ & $\begin{array}{l}\text { H1: "The quality of cleaning depends greatly on the } \\
\text { person doing it...especially for weekend staff and the } \\
\text { use of temps during vacation season, but we are } \\
\text { trying to solve the issue through training." }\end{array}$ & \multicolumn{5}{|c|}{ N/A } & N/A \\
\hline $\begin{array}{l}\text { Employee } \\
\text { engagement }\end{array}$ & $\begin{array}{l}\text { The extent to which the } \\
\text { employees feel } \\
\text { motivated to perform a } \\
\text { task and incentives for } \\
\text { performing tasks. }\end{array}$ & $\begin{array}{l}\text { Issues with low productivity } \\
\text { experienced, mainly due to lack } \\
\text { of incentives and motivation to } \\
\text { perform tasks and use } \\
\text { technologies. Another example is } \\
\text { lack of feeling responsibility and } \\
\text { pride due to transporter } \\
\text { centralization. }\end{array}$ & $\begin{array}{l}\text { H1: "There are over } 80 \text { ways of cleaning a room and } \\
\text { the employees need to learn the right way under for } \\
\text { circumstance. We pay for extensive training of the } \\
\text { employees and then they go off to a better paid job in } \\
\text { the private sector." } \\
\text { H1: "The quality of cleaning depends greatly on the } \\
\text { person doing it...especially for weekend staff and the } \\
\text { use of temps during vacation season, but we are } \\
\text { trying to solve the issue through training." }\end{array}$ & \multicolumn{5}{|c|}{ N/A } & N/A \\
\hline $\begin{array}{l}\text { Employee } \\
\text { work } \\
\text { conditions }\end{array}$ & $\begin{array}{l}\text { The conditions under } \\
\text { which employees work. } \\
\text { E.g. access to sunlight, } \\
\text { ergonomics etc. }\end{array}$ & $\begin{array}{l}\text { Working conditions for } \\
\text { employees cleaning beds have } \\
\text { historically been poor, although } \\
\text { recently improved, and tasks are } \\
\text { often physically strenuous, e.g. } \\
\text { pushing beds. }\end{array}$ & $\begin{array}{l}\text { H3: "We are establishing a new area for cleaning and } \\
\text { making beds, which will run on tracks, have } \\
\text { improved indoor climate, cranes will be used for } \\
\text { heavy lifting and there will be more natural light in } \\
\text { the room. Currently, the employees must walk } \\
\text { outside every hour due to no natural light and poor }\end{array}$ & & $\mathrm{X}$ & $\mathrm{X}$ & & & $\begin{array}{l}\text { To alleviate employees } \\
\text { from strenuous work. }\end{array}$ \\
\hline
\end{tabular}




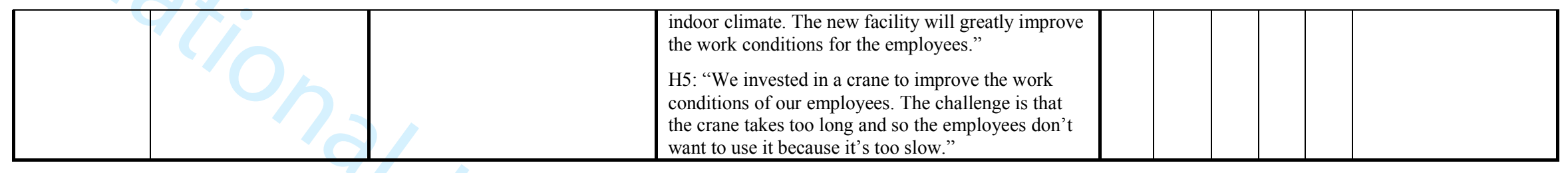


Table 3. List of impact factors serving as decision criteria

\begin{tabular}{llll}
\hline $\begin{array}{l}\text { Healthcare } \\
\text { environment }\end{array}$ & Technology & Process flow & $\begin{array}{l}\text { Organizational } \\
\text { structure }\end{array}$ \\
\hline - Future proofing & $\bullet \begin{array}{l}\text { Degree of } \\
\text { automation }\end{array}$ & $\bullet$ Lead time & $\bullet$ Competence shifts \\
- Security of supply & $\bullet$ Information & $\bullet$ Value-added time & $\bullet$ Competence match \\
- Impact on related & management & $\bullet$ Risk of mistakes & $\bullet$ Employee \\
processes & $\bullet$ Traceability & $\bullet$ Consistency & Employee work \\
- Output quality & & $\bullet$ Unnecessary process & conditions \\
- Environmental & & & \\
\hline
\end{tabular}


Table 4. Impact factors with assigned weights of importance

\begin{tabular}{|c|c|c|c|c|c|c|c|}
\hline \multirow[t]{2}{*}{ Impact factors } & \multirow{2}{*}{$\begin{array}{c}\begin{array}{c}\text { Low } \\
\text { techn. } \\
\text { adoption }\end{array} \\
\text { Hospital } 3\end{array}$} & \multicolumn{3}{|c|}{ Medium technology adoption } & \multirow{2}{*}{$\begin{array}{c}\text { High techn. } \\
\text { adoption }\end{array}$} & \multicolumn{2}{|c|}{$\begin{array}{c}\text { All } \\
\text { hospitals }\end{array}$} \\
\hline & & Hospital 1 & Hospital 4 & Hospital 5 & & $\mu$ & $\sigma$ \\
\hline $\begin{array}{l}\text { Risk of mistakes } \\
(P)\end{array}$ & 10 & 10 & 10 & 10 & 10 & 10.0 & - \\
\hline $\begin{array}{l}\text { Employee work } \\
\text { conditions }(O)\end{array}$ & 10 & 8 & 10 & 10 & 10 & 9.6 & 0.8 \\
\hline Consistency $(P)$ & 10 & 7 & 10 & 10 & 10 & 9.4 & 1.2 \\
\hline $\begin{array}{l}\text { Employee } \\
\text { engagement }(O)\end{array}$ & 10 & 7 & 10 & 10 & 10 & 9.4 & 1.2 \\
\hline $\begin{array}{l}\text { Security of } \\
\text { supply }(H)\end{array}$ & & 7 & 10 & 10 & 10 & 9.4 & 1.2 \\
\hline $\begin{array}{l}\text { Environmental } \\
\text { considerations } \\
\text { (H) }\end{array}$ & 10 & 7 & 10 & 8 & 10 & 9.0 & 1.3 \\
\hline $\begin{array}{l}\text { Value-added } \\
\text { time }(P)\end{array}$ & 9 & 5 & 10 & 8 & 10 & 8.5 & 1.9 \\
\hline Lead time $(P)$ & 10 & 4 & 10 & 8 & 10 & 8.4 & 2.3 \\
\hline $\begin{array}{l}\text { Information } \\
\text { management (T) }\end{array}$ & 10 & 5 & 10 & 9 & 8 & 8.4 & 1.7 \\
\hline $\begin{array}{l}\text { Impact on related } \\
\text { processes }(H)\end{array}$ & 10 & 5 & 8 & 9 & 10 & 8.3 & 1.8 \\
\hline $\begin{array}{l}\text { Future proofing } \\
(H)\end{array}$ & 9 & 4 & 8 & 10 & 10 & 8.0 & 2.1 \\
\hline $\begin{array}{l}\text { Output quality } \\
(H)\end{array}$ & 10 & 9 & - & 10 & 10 & 7.8 & 3.9 \\
\hline $\begin{array}{l}\text { Degree of } \\
\text { automation (T) }\end{array}$ & 9 & 6 & 7 & 7 & 10 & 7.8 & 1.5 \\
\hline Traceability (T) & 8 & 7 & 10 & 10 & 2 & 7.4 & 2.9 \\
\hline $\begin{array}{l}\text { Competence } \\
\text { shift }(O)\end{array}$ & 10 & 2 & 8 & 7 & 1 & 5.6 & 3.5 \\
\hline $\begin{array}{l}\text { Competence } \\
\text { match }(O)\end{array}$ & 4 & 3 & 10 & 10 & 1 & 5.6 & 3.7 \\
\hline $\begin{array}{l}\text { Unnecessary } \\
\text { process }(P)\end{array}$ & 9 & 3 & 8 & - & 5 & 5.0 & 3.3 \\
\hline
\end{tabular}

